\title{
Fluorescence-guided hepatobiliary surgery with long and short wavelength fluorophores
}

\author{
Thinzar M. Lwin ${ }^{1}$, Robert M. Hoffman ${ }^{1,2,3}$, Michael Bouvet ${ }^{1,3}$ \\ ${ }^{1}$ Department of Surgery, University of California San Diego, San Diego, CA, USA; ${ }^{2}$ AntiCancer, Inc., San Diego, CA, USA; ${ }^{3}$ VA San Diego \\ Healthcare System, San Diego, CA, USA \\ Contributions: (I) Conception and design: All authors; (II) Administrative support: None; (III) Provision of study material or patients: None; (IV) \\ Collection and assembly of data: TM Lwin; (V) Data analysis and interpretation: All authors; (VI) Manuscript writing: All authors; (VII) Final \\ approval of manuscript: All authors. \\ Correspondence to: Michael Bouvet, MD. Department of Surgery, University of California San Diego, Moores Cancer Center, 3855 Health Sciences \\ Drive \#0987, La Jolla, CA 92093-0987, USA. Email: mbouvet@ucsd.edu.
}

Importance: Fluorescence-guided surgery (FGS) is a potentially powerful tool for hepatobiliary (HPB) surgery. The high sensitivity of fluorescence navigation is especially useful in settings where tactile feedback is limited.

Objective: The present narrative review evaluates literature on the use of FDA-approved fluorophores such as methylene blue (MB), 5-aminolevulinic acid (5-ALA), and indocyanine green (ICG) for clinical intraoperative image-guidance during HPB surgery.

Evidence Review: Approaches such as dosing, timing, imaging devices and comparative endpoints are summarized. The feasibility and safety of fluorophores in visualizing the biliary tree, identify biliary leaks, outline anatomic hepatic segments, identify tumors, and evaluate perfusion and graft function in liver transplants are discussed.

Findings: Tumor-specific probes are a promising advancement in FGS with a greater degree of specificity. The current status of tumor-specific probes being evaluated in clinical trials are summarized.

Conclusions and Relevance for Reviews: Relevant discussion of promising tumor-specific probes in pre-clinical development are discussed. Fluorescence-guidance in HPB surgery is relatively new, but current literature shows that the dyes are reliably able to outline desired structures with a variety of dosing, timing, and imaging devices to provide real-time intra-operative anatomic information to surgeons. Development of tumor-specific probes will further advance the field of HPB surgery especially during oncologic resections.

Keywords: Fluorescence-guided surgery (FGS); methylene blue (MB); 5-aminolevulinic acid (5-ALA); indocyanine green (ICG); hepatobiliary surgery (HPB surgery); tumor-specific probes; near-infrared fluorescence (NIR fluorescence)

Submitted Mar 21, 2019. Accepted for publication Jul 12, 2019.

doi: $10.21037 /$ hbsn.2019.09.13

View this article at: http://dx.doi.org/10.21037/hbsn.2019.09.13

\section{Introduction}

A critical issue in surgical treatment of hepatobiliary (HPB) lesions is the need for accurate localization, resection, and reconstruction, while sparing parenchyma and preserving function. High-resolution, contrast-enhanced pre-operative imaging can approximate the lesion in relation to adjacent structures. However, these images are usually obtained weeks, or even months prior to surgery. Registration of these images with intra-operative anatomy can be imprecise. Once in the operating room, surgeons must rely on visual inspection, tactile palpation and clinical judgment to determine location and set resection margins.

The use of ultrasound and its incorporation into the intra- 
operative environment in the 1980's enhanced the precision of tumor localization (1). This gave surgeons the ability to visualize tumors in real-time. The use of intra-operative ultrasound (IOUS) improved the detection and localization of lesions by up to $35 \%$ when compared with traditional cross-sectional imaging (2). This is especially useful for lesions not readily visible on the surface of the liver.

Fluorescence imaging can further enhance the ability of surgeons to see lesions in real-time. Fluorescence is based on the use of an exogenous chromophore agent, which emits a signal when excited with light of a specific wavelength. Fluorophores within the visible spectrum emit a signal that is detectable with the naked eye while fluorophores at the near-infrared (NIR) spectrum require an imaging device to detect the signal (3). NIR fluorophores are more commonly used for intra-operative imaging due to decreased light scattering, auto-fluorescence, tissue absorption and increased tissue penetration $(4,5)$. Differential biodistribution of these agents are exploited for contrast enhancement of the surgical field.

The three commonly used, FDA-approved fluorophores for intra-operative imaging are: methylene blue (MB), 5 -aminolevulinic acid (5-ALA), and indocyanine green (ICG). The present literature review seeks to describe the clinical uses of these fluorophores in HPB surgery and highlight key relevant studies regarding efficacy. $M B$ is both a visible wavelength non-specific fluorophore when used at millimolar doses and an NIR $700 \mathrm{~nm}$ fluorophore when used at micromolar doses. 5-ALA is visible wavelength semispecific fluorophore. Both MB and 5-ALA have been used to a limited degree for fluorescence-guided HPB surgery and therefore will only be briefly discussed here. ICG is a non-specific NIR fluorophore and has a rapidly-expanding body of literature describing its applications for intraoperative guidance of HPB procedures. The use of ICG for visualizing the gallbladder, bile ducts, liver segments, liver tumors, and liver transplant will be discussed. While ICG as a NIR fluorophore is sensitive, it is not specific and tumor-specific fluorescent antibodies are an exciting next generation of probes. Currently, developing molecules and their status in clinical trials will also be reviewed here.

We present the following article in accordance with the Narrative Review reporting checklist (available at http:// dx.doi.org/10.21037/hbsn.2019.09.13).

\section{Methods}

A Medline search was performed via PubMed using the keyword "fluorescence" with the following HBP surgery related keywords: "cholecystectomy", "cholangiography", "bile duct", "hepatectomy", "hepatic resection", "liver resection", "hepatobiliary surgery", "liver transplant", "pancreatic surgery" in conjunction with the following 3 fluorophores "methylene blue", "5-ALA", "ICG". Studies on the use of fluorescence-guided surgery (FGS) for pancreatic surgery were deferred for the purpose of this manuscript. Original studies were retrieved and selected by authors for clinical relevance to FGS. Papers were selected for their use of fluorophores for clinical intra-operative image-guidance during HPB surgery. Approaches and uses of the fluorophores are summarized. Studies were required to be written in English, and accessible through the University of California Systems Library. Pre-clinical animal studies and reviews were not included here. Studies were organized into a database using Microsoft Excel and summarized into tables. In discussing tumor-specific NIR fluorescent probes, relevant pre-clinical studies are mentioned. To evaluate current status of FGS in clinical trials, a review of clinicaltrials.gov was performed using the following HPB surgery related key words with fluorescence related keywords such as "ICG", "fluorescence", "fluorescence-guided surgery", "fluorophore", and "nearinfrared as well as "tumor-specific probes". Additional searches were performed directly using the names of the principal investigators resulted on the initial query. References of the included articles were checked to ensure that no additional relevant studies were missed with the search criteria. The number of overall articles recovered and reviewed specific to each topic are summarized in Table 1.

\section{$M B$}

MB is a water soluble heptically and renally eliminated molecule which traditionally has been used at high millimolar doses for sentinel lymph node detection under bright light in melanoma and breast cancer (6). At low micromolar concentrations, it exhibits fluorescence properties, emitting a peak signal at $688 \mathrm{~nm}$ (7). The mechanism behind the accumulation of $\mathrm{MB}$ at tumors is unclear. Within the field of HPB surgery, MB has been used more commonly as a visible stain with white-light visualization rather than as a fluorophore for FGS. It has been used to delineate anatomic segments, check for bile leaks, and evaluate extrahepatic biliary structures. When using $\mathrm{MB}$ as a contrast agent during cholecystectomy, the dye is injected directly into the gallbladder infundibulum 
Table 1 Summary of number of articles reviewed for relevance to FGS

\begin{tabular}{|c|c|c|}
\hline Variable & Studies identified & Relevant studies \\
\hline \multicolumn{3}{|l|}{ MB } \\
\hline Cholecystectomy & 1 & 1 \\
\hline Cholangiography & 1 & 1 \\
\hline Bile duct & 3 & 2 \\
\hline Hepatectomy & 2 & 0 \\
\hline Hepatic resection & 1 & 1 \\
\hline Liver resection & 5 & 2 \\
\hline Liver surgery & 4 & 2 \\
\hline Hepatobiliary surgery & 1 & 0 \\
\hline Liver transplant & 0 & 0 \\
\hline \multicolumn{3}{|l|}{ 5-ALA } \\
\hline Cholecystectomy & 0 & 0 \\
\hline Cholangiography & 0 & 0 \\
\hline Bile duct & 1 & 0 \\
\hline Hepatectomy & 3 & 3 \\
\hline Hepatic resection & 4 & 3 \\
\hline Liver resection & 11 & 4 \\
\hline Hepatobiliary surgery & 0 & 0 \\
\hline Liver surgery & 26 & 5 \\
\hline Liver transplant & 6 & 0 \\
\hline \multicolumn{3}{|l|}{ ICG } \\
\hline Cholecystectomy & 39 & 33 \\
\hline Cholangiography & 44 & 33 \\
\hline Bile duct & 60 & 2 \\
\hline Hepatectomy & 51 & 28 \\
\hline Hepatic resection & 35 & 21 \\
\hline Liver resection & 87 & 33 \\
\hline Hepatobiliary surgery & 40 & 5 \\
\hline Liver surgery & 130 & 33 \\
\hline Liver transplant & 31 & 14 \\
\hline
\end{tabular}

MB, methylene blue; 5-ALA, 5-aminolevulinic acid; ICG, indocyanine green. to outline the extrahepatic biliary tree (8). During liver surgery, $\mathrm{MB}$ can be directed to the segment to be removed via injection of dye into the appropriate portal vein branch under ultrasound guidance (9). MB was found to be most useful during parenchymal dissection as there was a clear color difference between the two areas beyond surface boundaries (10). When used to detect bile leaks at the cut edge of the liver, the dye is injected through a trans-cystic tube. In several studies, the postoperative biliary leakage rate was reduced by the $\mathrm{MB}$ test $(3.6 \%$ vs. $7.3 \%, \mathrm{P}<0.05)$ and on multivariate analysis, the absence of an $M B$ test was an independent risk factor for a bile leak (OR $=2.6,95 \%$ CI: $1.43-4.65, \mathrm{P}=0.002)(11,12)$. In transplant surgery, it was used to demonstrate that abdominal drains were not needed after donor hepatectomies if the MB bile leak test was negative (13).

MB has more commonly been used as a visible dye under white light for HPB procedures, but due to the superior tissue penetration of NIR fluorescence and its ability to emit a signal at around $700 \mathrm{~nm}$, it has recently been explored as an agent for FGS. While there is limited use of MB for FGS described in the clinical literature, it has been compared against ICG in some pre-clinical studies and the advantages of a low liver signal, rapid fluorescence (within 5-20 minutes), and possibility of repeat dosing were noted $(14,15)$. The disadvantages are that the signal overall is weaker and the mechanism by which $\mathrm{MB}$ accumulates at lesions is unclear. The dye also has the potential adverse effects of interfering with pulse oximetry, skin or urine discoloration, and anaphylaxis and hemolysis in G6PDdeficient patients.

As a fluorophore for fluorescence-guided HPB procedures, $\mathrm{MB}$ has only been examined in isolated case reports. There were no studies evaluating the use of $M B$ in fluorescence-guided hepatectomies, cholecystectomies, or in liver transplants.

\section{5-ALA}

5-ALA is a water-soluble molecule that is processed by the porphyrin synthesis pathway into protoporphyrin IX (PPIX) that emits a peak signal at $635 \mathrm{~nm}$ (16). PPIX in normal cells is converted to heme by ferrochelatase (FC) in mitochondria 
and eventually excreted into bile after heme is converted to biliverdin and bilirubin in the cytoplasm. The fluorophore is semi-selective. The fluorescence signal in cancer cells is due to increased porphobilinogen deaminase (PBG-D) synthesis of PPIX and decreased activity of FC, leading to an overall preferential accumulation of PPIX at tumors (17). 5-ALA can penetrate the blood-brain barrier and this property has been exploited for FGS of brain tumors (18). It has also been utilized in dermatology and urology for detection of lesions $(19,20)$.

Regarding HPB procedures, 5-ALA has been evaluated for visualization of liver lesions. There are 5 studies describing the use of 5-ALA for visualization in the literature. Schneider et al. first described fluorescence intraoperative imaging of hepatocellular carcinoma (HCC) (described as "photodynamic diagnosis" or PDD) in a case report of a patient with HCC who was found to have additional hepatic micro-metastases which would have been missed with conventional white-light laparoscopy (21). In this case report, they used an oral solution of $20 \mathrm{mg} / \mathrm{kg}$ 5-ALA and imaged with the Storz D-Light AF-system laparoscope (Karl Storz GmbH, Tuttlingen, Germany) 6 hours after administration. In their subsequent case series they reported that the use of fluorescence imaging yielded detection of more metastatic lesions in 4 of 9 patients compared to white light (22). While the work demonstrated the feasibility of detection, it did not describe the surgical resection based on fluorescence-guidance.

Work by Inoue et al. describes the largest experience with 5-ALA-based FGS. The group first described their experience with a series of 70 patients who underwent liver resection for liver tumors (23). The patients had oral administration of 1 gram of 5 -ALA in $20 \mathrm{~mL} 50 \%$ glucose solution 3 hours prior to surgery and imaging was performed with a specific blue light (Esperaluz ESLZ-PDHLVL405; CCS Inc., Kyoto, Japan) and a SC-52 Fuji filter (Fuji Film, Tokyo, Japan) for open surgeries and a Storz D-Light AF-laparoscope (Karl Storz GmbH, Tuttlingen, Germany) for minimally-invasive procedures. They note that the technology was most useful for tumors on the surface of the liver and was especially useful in laparoscopic surgery where palpation is limited. It was effective for margin assessment during parenchymal transection. There was a $100 \%$ sensitivity for detection of HCC, $85.7 \%$ for colorectal liver metastases (CLM), and $100 \%$ for liver tumors of various etiologies with an overall sensitivity of 5-ALA for detection of $92.5 \%$. The margins of resection were negative for all patients in the case series (vs. $8 \%$ in their historical controls) despite having significantly smaller margin width in the specimen of $6.7 \pm 6.9$ (range $0-27) \mathrm{mm}[v s .9 .2 \pm 7.0$ (range $0-47) \mathrm{mm}$ in their historical controls] $(\mathrm{P}=0.0083)$ that was attributable to fluorescence guidance. The same group compared the use of 5-ALA and ICG in 134 patients using 5-ALA, 1 gram given 3 hours before surgery with imaging devices as described above, and $0.5 \mathrm{mg} / \mathrm{kg}$ of ICG intravenously 14 days after surgery using photodynamic eye (PDE) (Hamamatsu Photonics, Shizuoka, Japan) for imaging. The sensitivity, specificity and accuracy of 5-ALA for detecting the main tumors were $57 \%, 100 \%$ and $58 \%$, respectively, compared to the sensitivity, specificity and accuracy of ICG of $96 \%, 50 \%$ and $94 \%$ respectively. The use of fluorescence technology allowed detection of 5 additional lesions missed by preoperative imaging. They noted that ICG was more sensitive and less specific while 5-ALA was more specific but less sensitive, but both were useful in detecting small superficial tumors on the liver surface.

Inoue et al. also retrospectively evaluated the use of 5-ALA PDD for visualization of bile leaks in the above cohort of patients (24). As the metabolized product is extracted in the bile, it is detectable by fluorescence. Rather than retrograde injection of various dyes at non-physiologic pressures, the physiologic metabolism and biliary excretion after oral 5-ALA intake make it useful for detection of bile leaks at physiologic draining pressures without the use of catheters to cannulate the biliary tree. There were 9 patients with intra-operatively detected bile leaks, but the use of fluorescence imaging with 5-ALA showed a bile leak in 6 additional patients. They concluded that there was a statistically-significant difference although they number of patients who had bile leaks diagnosed using 5-ALA fluorescence imaging was very small.

5-ALA is a useful, orally-administered compound for intra-operative fluorescence imaging and guidance of liver lesions and bile leaks. It has not been described for use in fluorescence-guided cholecystectomy or liver transplant. 5-ALA is a semi-selective fluorophore for tumors based on their aberrant metabolism of the dye. It is more specific than either MB or ICG based on the limited literature available. It has limited signal in the hepatic parenchyma, but is more concentrated in bile, making it potentially useful to evaluate bile leaks. Drawbacks are that it is a visible wavelength fluorophore and is very limited in visualizing deeper lesions, an issue commonly described in the studies mentioned above. While minor, its route of oral administration can be an issue in patients who are 
unable to tolerate any oral intake. Additionally, it appears to cause adverse reactions such as photodermatosis (sunburn) needing 24 hour avoidance of sunlight exposure, GI upset, and abnormalities in liver function tests $(25,26)$.

\section{ICG}

ICG is a water-soluble molecule that binds to plasma proteins, undergoes hepatic metabolism and biliary elimination (27). It was initially used for fundoscopy and estimation of cardiac and hepatic function (28). However due to its vascular partitioning, near exclusive biliary elimination mechanisms, and low toxicity, it has been used for a number of surgical procedures. ICG emits at NIR wavelengths with a peak signal at $830 \mathrm{~nm}$ that allows for increased tissue depth penetration of up to $10 \mathrm{~mm}$ (29). There are a wide array of ICG-optimized surgical imaging devices available $(5,30)$. The NIR wavelength window also has decreased auto-fluorescence leading to background noise and increased contrast of the visualized structure (4). ICG has been widely used to evaluate tissue perfusion and lymphatic mapping. Within the field of HPB surgery, the hepatic metabolism of ICG makes it useful for many intraoperative real-time imaging approaches. It is especially useful for non-invasive fluorescence cholangiography to evaluate the biliary tree. It can be used to selectively perfuse segments of the liver to better identify the boundaries of anatomic resection as well as to detect bile leakage after hepatic resections. Due to the enhanced permeability and retention (EPR) of ICG by disorganized neoplastic tissue, it is also useful in oncologic procedures, especially visualizing cancers of the HPB system.

\section{ICG for evaluating the gallbladder and biliary tree}

Intra-operative cholangiography (IOC) has been essential for intra-operative visualization of the biliary tree since its first introduction in 1930's by Dr. Mirizzi (31). The use of IOC allows surgeons to better define the biliary anatomy, achieve early recognition and decrease severity of biliary injury should it occur (32). However, IOC is often cumbersome, resource-intensive, requires $\mathrm{X}$-ray exposure, and administration of contrast which is invasive as it requires cannulation of the biliary tree. There can also be anatomic limitations to IOC especially in the setting of severe cholecystitis with friable tissue leading to inability to cannulate and further dissection would lead to increased risk of biliary injury.
Ishizawa first showed feasibility of ICG cholangiography to evaluate the biliary system by comparing trans-cystic administration and intravenous administration of ICG in 2008 using an open-field NIR fluorescence imaging device in patients undergoing open donor hepatectomy or open cholecystectomy (33). This approach was adapted into a minimally-invasive setting using intravenous ICG administration with a fluorescence laparoscope for patients undergoing laparoscopic cholecystectomy. In all 52 patients, the cystic duct was easily identified, and in 50 patients the cystic to common hepatic duct junction was easily identified under fluorescence prior to any dissection (34). After dissection, the cystic to common hepatic duct junction was identified in all patients under fluorescence imaging. The technology also identified unusual biliary anatomy such as accessory hepatic ducts and unusual cystic to common hepatic duct junctions, such as short cystic ducts and parallel or spiral junctions which place patients at high risk of bile duct injuries.

There were 33 different studies from different groups reporting on the results of their studies of cholecystectomies under fluoresence guidance. They are summarized in Table 2. Fluorescence-guidance is useful in helping identify the cystic duct-common bile duct (CD-CBD) junction during cholecystectomies for many indications: cholelithiasis, acute cholecystitis, chronic cholecystitis, or cholecystitis needing a percutaneous cholecystostomy tube. Optimal dosing of ICG and timing of visualization are still variable, as demonstrated in Table 2, a dose of $2.5 \mathrm{mg}$ intravenous approximately 1-2 hours prior to surgery seems to be the most widely used approach with acceptable liver background fluorescence. There is variability in approaches to dye delivery: intravenous vs. direct biliary injection. Regardless of the dose, schedule and route, the use of ICG was effective in identifying the critical view of safety (CVS) during different approaches to cholecystectomies in the reviewed studies. These groups looked at laparoscopic, robotic, or single-incision approaches to fluorescenceguided cholecystectomies using a variety of fluorescenceenabled scopes. Hammamatsu, Storz, Stryker, Noavadaq, Olympus, and DaVinci Flirefly are the most commonly used in the operating room. The strength of the light source, the sensitivity of the camera capturing images, the proprietary software to process the image and render a "threshold" to display a positive fluorescence signal, as well as the final image output format (black and white $v s$. color overlay $v s$. intensity-based heat map) are heterogeneous and variable across different devices. All these above factors affect the 


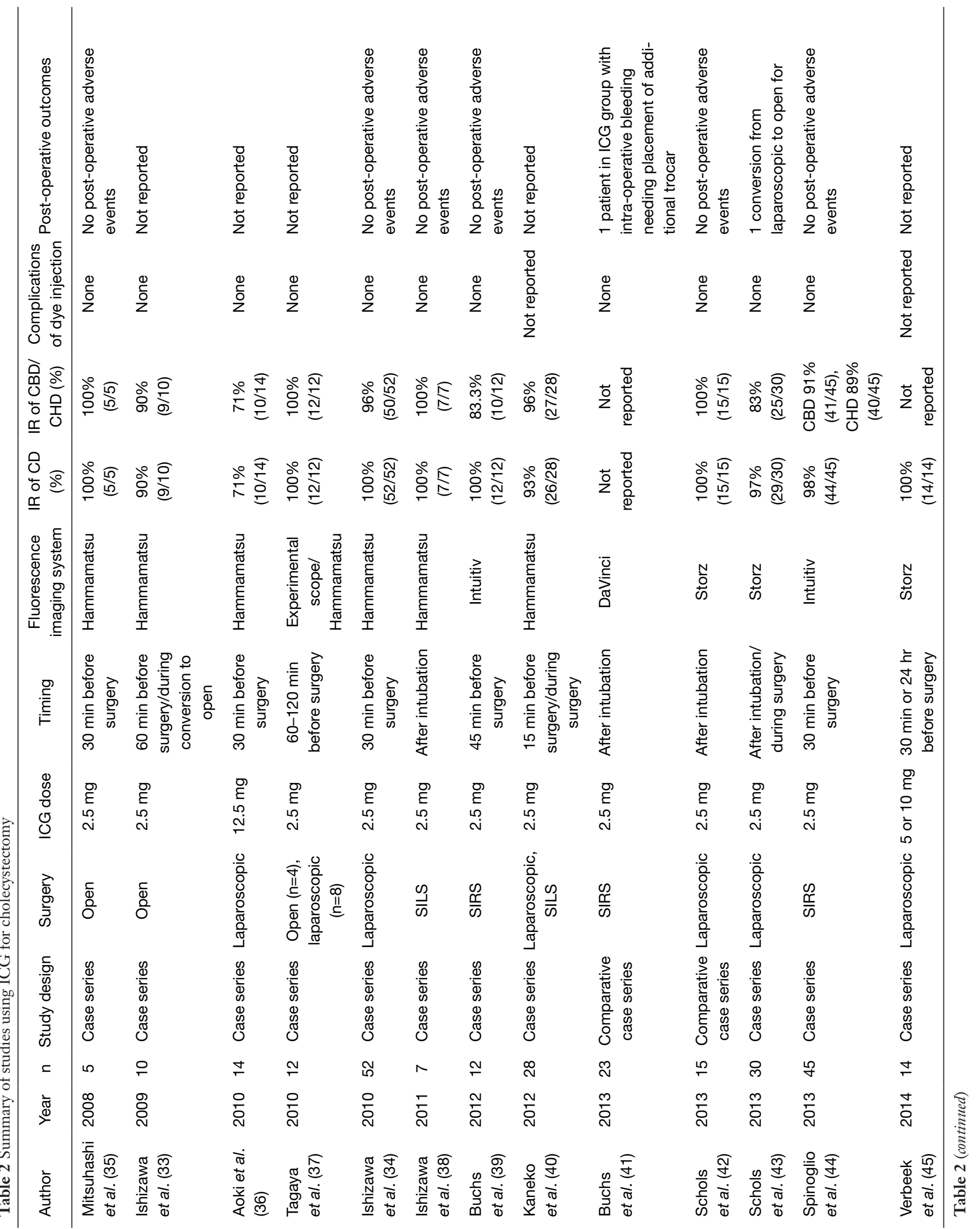




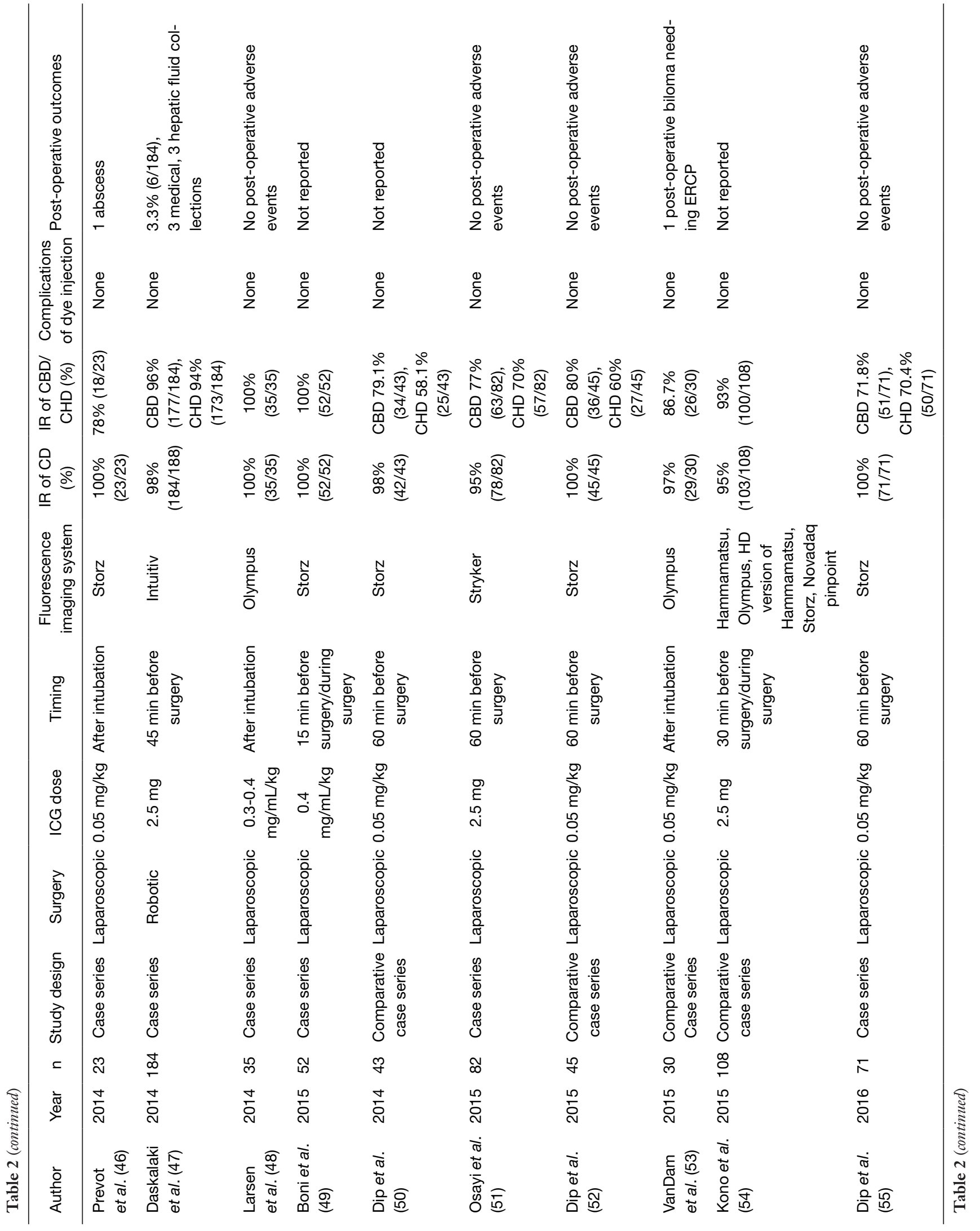




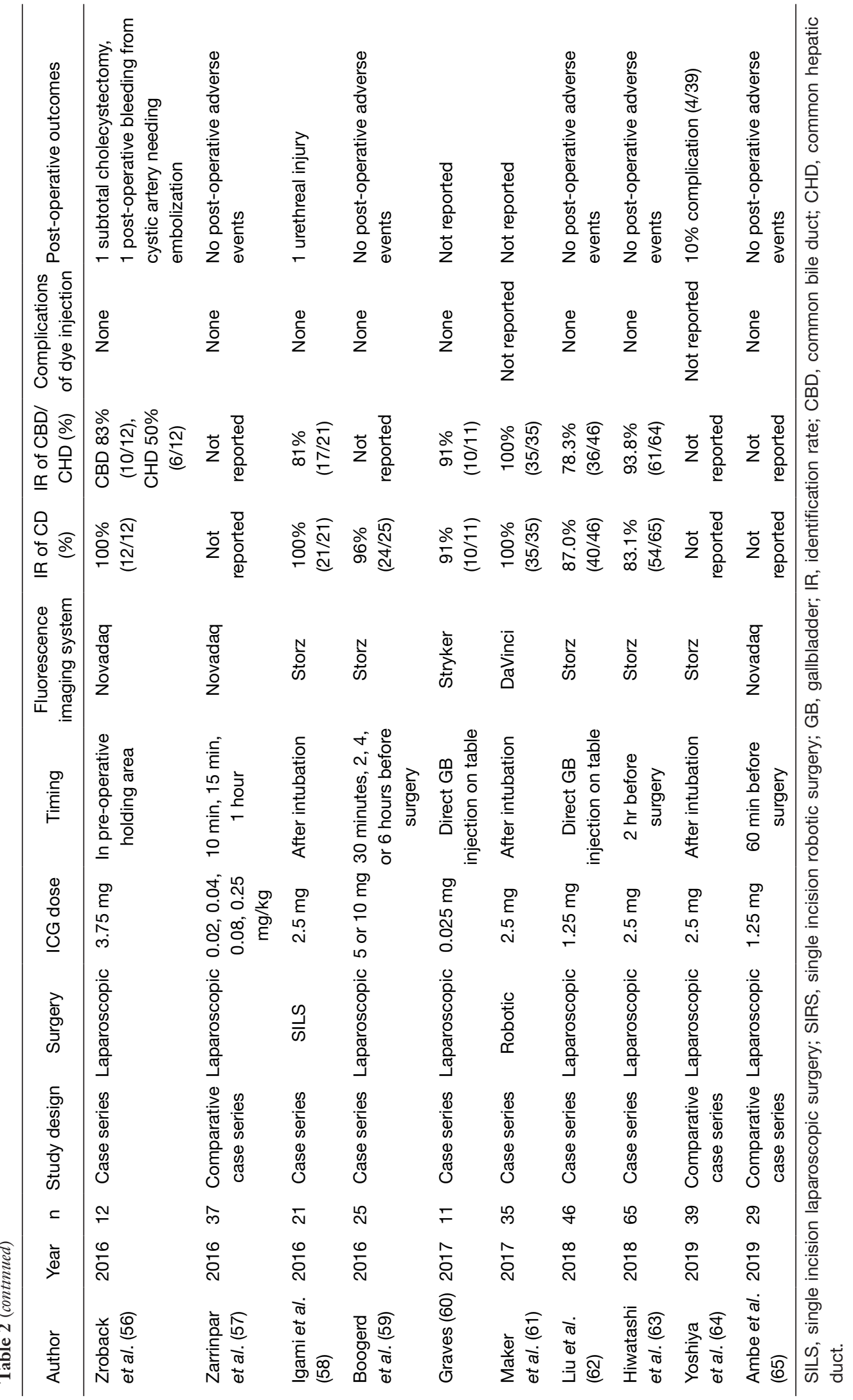


quality of the image that the surgeon can use. As these variables are heterogenous, it is difficult to directly compare them. Consensus of the available literature in this specific application of ICG FGS is very encouraging. Compared to bright-light surgery, most studies found that the use of ICG fluorescence guidance led to a higher identification rate of the cystic duct, the CD-CBD junction, the CVS, a shorter time to identification of vital structures, clearer dissection plane between the gallbladder and hepatic fossa, and improved identification of accessory hepatic ducts or recognition of aberrant anatomy if present. Boni et al. comment that they were able to identify the biliary anatomy in all cases where ICG was used, irrespective of whether the tissue was normal or inflamed (49). Contrary to this, Hiwatashi et al. noted that the group in which the CD was not identified, had a higher likelihood of inflammatory markers and clinical diagnosis of acute cholecystitis (63).

While the data on outcomes is even more limited, of the groups that report it, there were no major adverse reactions to dye administration and there were decreased rates of conversion to open surgery, decreased rates of subtotal cholecystectomies, shorter operative times. Schols et al. reported significantly earlier identification of the CD (ICG 23 min vs. standard $31 \mathrm{~min}, \mathrm{P}=0.004$ ) and the CBD (ICG 22 min vs. standard $32 \mathrm{~min}, \mathrm{P}=0.001$ ) (42). Buchs et al. found a significantly shorter operative time by $24 \mathrm{~min}$ compared to standard bright light single-incision robotic cholecystectomy $(\mathrm{P}=0.06)$ (41). While they did not report identification rates, they noted that the decreased operative time was attributable to earlier identification of the CVS. This difference was significant only for patients with bodymass index (BMI) less than 24 as the thickness of the fat pad around the biliary tree led to limited ICG penetration and optimal CVS visualization. This was also supported by work by Daskalaki and Osayi et al. that specifically looked at group stratification by BMI.

As fluorescence-based IOC has little risk, the cost of the dye itself is low, and fluorescence-enabled laparoscopes are more widely available, many surgeons familiar with fluorescence technology favor its routine use. Proponents of FGS technology argue that the barrier to use of fluorescence-based cholangiography is low and technical feasibility is uncomplicated. The cost-effectiveness of this approach was evaluated by Dip et al, comparing the cost of IOC and fluorescence-based IOC (52). They found that the use of fluorescence IOC was more cost effective when compared to IOC at $13.97 \pm 4.3$ USD vs. $778.43 \pm 0.4$ USD per patient $(\mathrm{P}=0.0001)$ without the need to cannulate the
CD. They note that the cannulation of the CD is one of the main points of contention by those who are adverse to routine IOC to prevent bile duct injury. If the wrong duct has been identified and cannulated, an IOC will prevent further injury such as complete transection of the CBD, but the choledochotomy will still need to be repaired.

However, incidences of biliary injuries during standard laparoscopic cholecystectomy are low and selective IOC is now preferred in most centers. There is not yet enough data to determine if fluorescence-cholangiography will affect rates of bile duct injury and or overall patient outcomes. Studies are ongoing to determine the added value of fluorescence cholangiography compared to conventional laparoscopic cholecystectomy. A number of studies compared fluorescent cholangiogram to IOC, while others compared FGS to standard bright light surgery (Table 3). Common end points are "time to identification of critical view of safety" "rate of identification of anatomic structures" and common secondary end points are "OR time", "outcomes", and "cost".

\section{ICG for visualizing bile leaks}

Besides IOC, ICG is useful in evaluating the biliary system during hepatic resections as a tool for evaluating bile leaks. While the use of ICG for visualizing intrahepatic bile ducts is limited due to tissue depth penetration, it is useful to evaluate details over the cut surface of the liver. Kaibori et al. and Sakaguchi et al. both described the approach using a cholangiocatheter cannulation of the cystic duct stump to deliver ICG $(66,67)$. Both studies showed that the use of ICG led to increased rates of detection of bile leaks compared to standard of care using a saline or fat emulsion injection. After repair, this led to no post-operative bile leaks in the ICG group in both studies compared to $6 \%$ and $10 \%$ respectively in the standard of care groups. The use of fluorescence imaging over the surgical bed of hepatic resections increased the rate of detection of bile leaks and subsequent complications.

\section{ICG for visualizing bepatic segments}

Anatomic resection of the liver based on Couinad segments revolutionized liver surgery by allowing surgeons to be methodical about the tissue that is removed while preserving healthy parenchyma (68). While intraoperative ultrasound is useful in visualizing the adjacent relationships of the vasculature, biliary structures and the lesion to be removed 


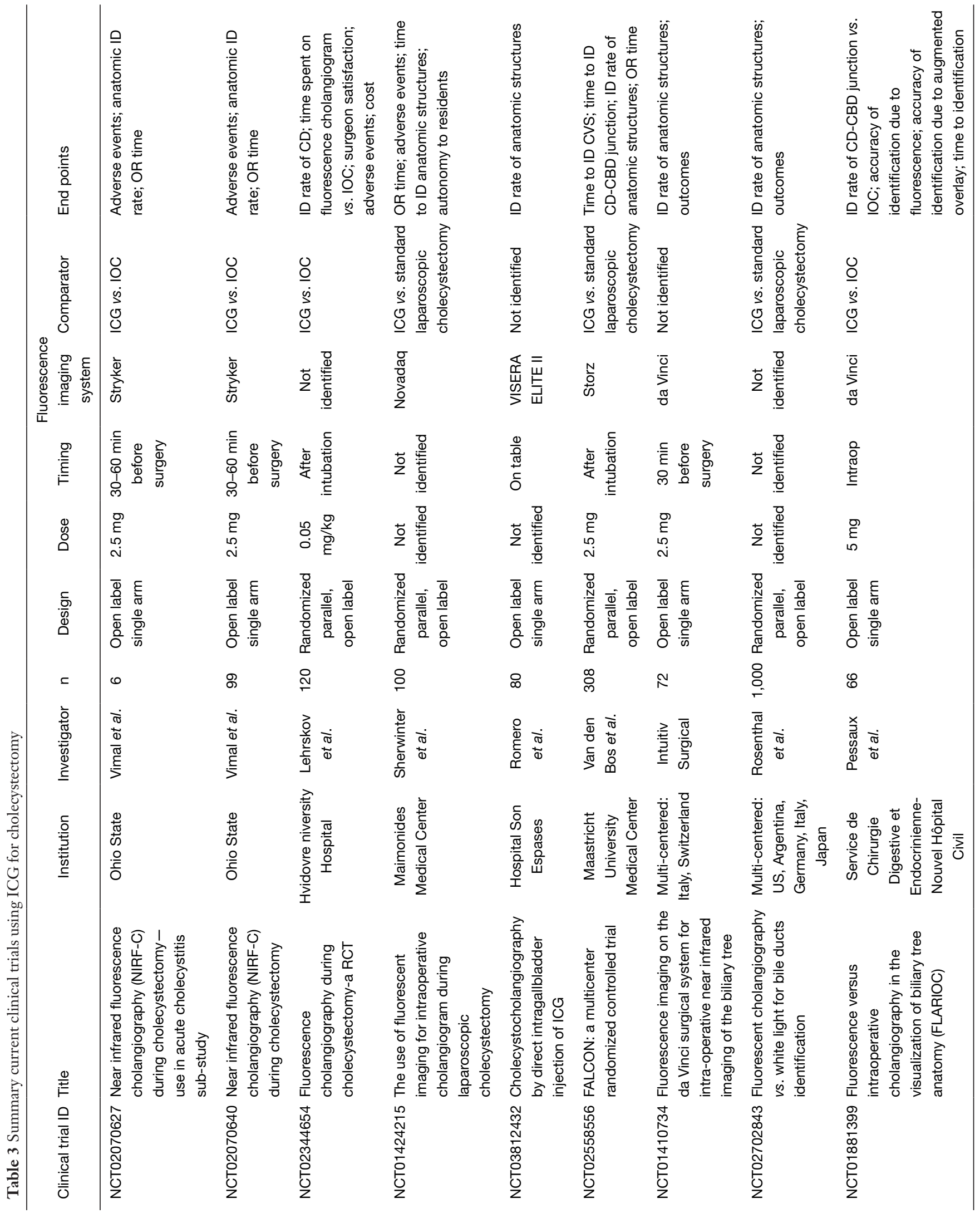


in real-time, the determination of resection boundaries at the level of hepatic surface anatomy is still often difficult to determine. A variety of techniques have been used to better delineate the anatomic segments prior to initiating parenchymal transection. Selective ligation of vascular pedicles and subsequent visualization of the ischemic boundaries is one approach. Dye injection as demonstrated by Makuuchi is another (69). A major issue with the use of traditional dyes such as MB and indigo-carmine, is the rapid washout after injection. The active transport of ICG and liver specificity of its metabolism allow the fluorescence signal from ICG to persist throughout the operation for continued image guidance. Aoki et al. and Inoue et al. first showed the feasibility of this approach, especially when following the intersegmental planes during division of the liver parenchyma $(70,71)$. Twelve out of the 33 papers relevant to FGS hepatic resections looked at segmental staining to help guide parenchymal resection (Table 4). These are given as either standard doses of $2.5-5 \mathrm{mg}$ or weightbased at $0.25-0.5 \mathrm{mg} / \mathrm{kg}$. Administration of the dye can be performed intraoperatively. Positive segmental staining can be obtained by selective portal vein injection while negative segmental staining can be obtained by intravenous injection during selective portal clamping. While there is increasing literature describing surgeons' experiences and case series in this area, there is little to no information on outcomes. As technology and experience with this approach expands the information should be forthcoming.

\section{ICG for visualizing hepatic tumors}

The vasculature of neoplastic tissue is leaky and poorly organized, an effect called the EPR effect (103). This leads to retention of ICG in distinct patterns with certain HPB neoplasms that lend itself to utility in fluorescence-guided oncologic procedures. Ishizawa and Gotoh were the first groups to describe the use of ICG fluorescence to localize hepatic lesions $(72,73)$. Patients received intravenous ICG as part of a routine pre-operative liver function assessment and the persistent signal at the tumors from this test was used to navigate resection margins. Twenty-one out of the 33 articles relevant to ICG fluorescence hepatectomy used this approach to label the tumor for intra-operative guidance. Gotoh et al. described HCC lesions as a bright homogenous fluorescence signal (72). They were able to detect all 10/10 pre-operatively diagnosed lesions, and in eight cases, new surface nodules not detected by either pre-operative imaging or IOUS were detected with the use of fluorescence imaging, 4/8 were HCC. Ishizawa described 37 patients with HCC and 12 patients with CLM, 23 of whom had the specimen imaged after resection with fluorescence imaging and 26 had real-time intra-operative fluorescence imaging after hepatic mobilization. They described three patterns of fluorescence: a bright homogenous fluorescence signal seen most commonly with HCC lesions, partial fluorescence seen in HCC lesions with components of hemorrhagic necrosis, and ring type fluorescence seen in CLM. Fluorescence microscopy for HCC lesions showed that the fluorescence was within the cancerous cells whereas in CLM lesions, the fluorescence was located at the surrounding non-cancerous liver parenchyma compressed by the tumor. Figure 1 adapted from Ishizawa's review on ICG fluorescence imaging for HPB cancer shows these fluorescence patterns (104). Uchiyama used ICG in conjunction with contrast-enhanced IOUS to detect CLM and found that these lesions did not fluoresce homogenously compared to HCC and most were ring enhancing $(n=18)$ (74). They found that the sensitivity of contrast-enhanced IOUS in conjunction with ICG fluorescence imaging was superior to multiple detector computed tomography (MDCT)/magnetic resonance imaging (MRI), 98.1\% vs. $88.5 \%(\mathrm{P}=0.05)$. They saw that even lesions that radiographically disappeared with neoadjuvant chemotherapy still showed a fluorescence signal and were positive for microscopically-viable cancer cells on pathology. Boogerd et al. reported on the use of ICG for hepatic resection of a wide variety of lesions including intrahepatic cholangiocarcinoma and hepatic metastases of uveal melanoma and breast cancer (59). These lesions showed a rim type fluorescence similar to CLM lesions.

Since the initial report of the use of ICG in hepatic resections, several hundred cases have been reported with a variety of timing and dosing of administration and overall, a good sensitivity ranging from $70-100 \%$ up to $10 \mathrm{~mm}$ depth (105). While the safety and efficacy of ICG administration has been well reported, the longterm outcomes after fluorescence-guided hepatic resection compared to conventional resection is unclear. Handgraaf et al. showed that the use of fluorescence imaging increased the number of additional lesions detected during surgery for CLM to $25 \%$ from $13 \%(\mathrm{P}=0.04)$ and the lesions detected by fluorescence imaging were usually smaller $3.2 \pm 1.8$ vs. $7.4 \pm 2.6 \mathrm{~mm}(\mathrm{P}<0.001)(106)$. While was an improvement in liver-specific recurrence-free survival at 4 years of $47 \%$ using fluorescence compared to $39 \%$ with conventional surgery, the study was not powered sufficiently to detect a significant difference. Further studies will need 
Table 4 Summary of studies using ICG for hepatectomy

\begin{tabular}{|c|c|c|c|c|c|c|c|c|c|}
\hline Authors & Year & $\mathrm{n}$ & Dose & Route & Timing & $\begin{array}{l}\text { Fluorescence } \\
\text { imaging system }\end{array}$ & Surgery & Tumors & $\begin{array}{l}\text { Staining } \\
\text { type }\end{array}$ \\
\hline $\begin{array}{l}\text { Aoki et al. } \\
\text { (70) }\end{array}$ & 2008 & 35 & $5 \mathrm{mg}$ & $\begin{array}{l}\text { Injection into } \\
\text { PV branch }\end{array}$ & Intraop & Hammamatsu & Open & $\begin{array}{l}13 \text { HCC, } 18 \text { liver } \\
\text { metastases, } \\
4 \text { CholangioCA }\end{array}$ & $\begin{array}{l}\text { Segmental } \\
\text { stain }\end{array}$ \\
\hline $\begin{array}{l}\text { Gotoh } \\
\text { et al. (72) }\end{array}$ & 2009 & 10 & $0.5 \mathrm{mg} / \mathrm{kg}$ & Intravenous & $\begin{array}{l}1-8 \text { days } \\
\text { before surgery }\end{array}$ & Hammamatsu & Open & $10 \mathrm{HCC}$ & $\begin{array}{l}\text { Tumor } \\
\text { stain }\end{array}$ \\
\hline $\begin{array}{l}\text { Aoki et al. } \\
\text { (36) }\end{array}$ & 2010 & 81 & $5 \mathrm{mg}$ & $\begin{array}{l}\text { Injection into } \\
\text { PV branch }\end{array}$ & Intraop & Hammamatsu & Open & $\begin{array}{l}28 \mathrm{HCC}, 35 \mathrm{CLM}, 8 \\
\text { CholangioCA, } 10 \text { other }\end{array}$ & $\begin{array}{l}\text { Segmental } \\
\text { stain }\end{array}$ \\
\hline $\begin{array}{l}\text { Uchiyama } \\
\text { et al. (74) }\end{array}$ & 2010 & 32 & $0.5 \mathrm{mg} / \mathrm{kg}$ & Intravenous & $\begin{array}{l}2 \text { weeks } \\
\text { before surgery }\end{array}$ & Hammamatsu & Open & 32 CLM & $\begin{array}{l}\text { Tumor } \\
\text { stain }\end{array}$ \\
\hline $\begin{array}{l}\text { Peloso } \\
\text { et al. (77) }\end{array}$ & 2013 & 25 & $0.5 \mathrm{mg} / \mathrm{kg}$ & Intravenous & $\begin{array}{l}24 \text { hours } \\
\text { before surgery }\end{array}$ & Hammamatsu & Open & 25 CLM & $\begin{array}{l}\text { Tumor } \\
\text { stain }\end{array}$ \\
\hline $\begin{array}{l}\text { Tanaka } \\
\text { et al. (78) }\end{array}$ & 2013 & 33 & $0.5 \mathrm{mg} / \mathrm{kg}$ & Intravenous & $\begin{array}{l}2 \text { days before } \\
\text { surgery }\end{array}$ & Hammamatsu & Open & $\begin{array}{l}10 \text { cirrhotic livers, } \\
23 \text { non-cirrhotic } \\
\text { (specifically } 12 \text { HCC, } \\
9 \text { CLM, } 1 \text { CholangioCA, } \\
1 \text { hepatic carcinoid) }\end{array}$ & $\begin{array}{l}\text { Tumor } \\
\text { stain }\end{array}$ \\
\hline $\begin{array}{l}\text { Kudo } \\
\text { et al. (79) }\end{array}$ & 2014 & 17 & $0.5 \mathrm{mg} / \mathrm{kg}$ & Intravenous & $\begin{array}{l}2 \text { weeks } \\
\text { before surgery }\end{array}$ & Olympus & Laparoscopic & $\begin{array}{l}10 \text { HCC, } 6 \text { CLM, } \\
1 \text { uterine cancer }\end{array}$ & $\begin{array}{l}\text { Tumor } \\
\text { stain }\end{array}$ \\
\hline $\begin{array}{l}\text { Barabino } \\
\text { et al. (83) }\end{array}$ & 2016 & 3 & $0.25 \mathrm{mg} / \mathrm{kg}$ & Intravenous & $\begin{array}{c}24 \text { hours } \\
\text { before surgery }\end{array}$ & Fluoptics & Open & $\begin{array}{l}2 \text { endocrine liver } \\
\text { metastasis, } 1 \text { CLM }\end{array}$ & $\begin{array}{l}\text { Tumor } \\
\text { stain }\end{array}$ \\
\hline $\begin{array}{l}\text { Kaibori } \\
\text { et al. (84) }\end{array}$ & 2016 & 48 & $0.5 \mathrm{mg} / \mathrm{kg}$ & Intravenous & $\begin{array}{l}14 \text { days before } \\
\text { surgery }\end{array}$ & Hammamatsu & Open & $\begin{array}{l}31 \mathrm{HCC}, 13 \mathrm{CLM}, 2 \\
\text { CholangioCA, } 2 \text { benign }\end{array}$ & $\begin{array}{l}\text { Tumor } \\
\text { stain }\end{array}$ \\
\hline $\begin{array}{l}\text { Takahashi } \\
\text { et al. (85) }\end{array}$ & 2016 & 15 & $5-7.5 \mathrm{mg}$ & Intravenous & $\begin{array}{l}1-2 \text { days } \\
\text { before surgery }\end{array}$ & $\begin{array}{l}\text { Intuitive, } \\
\text { Novadaq }\end{array}$ & $\begin{array}{l}\text { Open, } \\
\text { laparoscopic, } \\
\text { robotic }\end{array}$ & $\begin{array}{l}9 \mathrm{CLM}, 2 \\
\text { neuroendocrine, } \\
1 \mathrm{FNH}, 1 \text { hemangioma }\end{array}$ & $\begin{array}{l}\text { Tumor } \\
\text { stain }\end{array}$ \\
\hline $\begin{array}{l}\text { Zhang } \\
\text { et al. (86) }\end{array}$ & 2017 & 50 & $0.25 \mathrm{mg} / \mathrm{kg}$ & $\begin{array}{l}\text { Injection into PV, } \\
\text { Rt gastric vein, } \\
\text { central venous } \\
\text { catheter }\end{array}$ & Intraop & Hammamatsu & Open & $\begin{array}{l}38 \text { HCC, } 4 \text { cavernous } \\
\text { hemangiona, } \\
3 \text { CholangioCA, } 2 \text { CLM, } \\
1 \text { Malignant fibrous } \\
\text { histiocytoma, } \\
2 \text { micronodular cirrhosis }\end{array}$ & $\begin{array}{l}\text { Segmental } \\
\text { stain }\end{array}$ \\
\hline $\begin{array}{l}\text { Kawaguchi } \\
\text { et al. (87) }\end{array}$ & 2017 & 21 & $\begin{array}{c}2.5 \mu \mathrm{g} / \mathrm{mL} \text { of } \\
\text { total liver volume } \\
\text { estimated from } \\
\text { 3D CT }\end{array}$ & $\begin{array}{l}\text { Intravenous after } \\
\text { segmental HV, } \\
\text { PV, HA clamping }\end{array}$ & Intraop & Hammamatsu & Open & $\begin{array}{l}9 \text { HCC, } 9 \text { CLM, } \\
3 \text { others }\end{array}$ & $\begin{array}{l}\text { Segmental } \\
\text { stain }\end{array}$ \\
\hline
\end{tabular}

Table 4 (continued) 
Table 4 (continued)

\begin{tabular}{|c|c|c|c|c|c|c|c|c|c|}
\hline Authors & Year & $\mathrm{n}$ & Dose & Route & Timing & $\begin{array}{l}\text { Fluorescence } \\
\text { imaging system }\end{array}$ & Surgery & Tumors & $\begin{array}{l}\text { Staining } \\
\text { type }\end{array}$ \\
\hline $\begin{array}{l}\text { Terasawa } \\
\text { et al. (88) }\end{array}$ & 2017 & 41 & $\begin{array}{c}0.5 \mathrm{mg} / \mathrm{kg} \\
\text { preoperatively, } \\
1.25 \mathrm{mg} \\
\text { intraoperatively }\end{array}$ & Intravenous & $\begin{array}{l}3 \text { days before } \\
\text { surgery and } \\
\text { intraop }\end{array}$ & Novadaq & Laparoscopic & $\begin{array}{l}7 \text { HCC, } 46 \text { CLM, } \\
6 \text { others }\end{array}$ & $\begin{array}{l}\text { Tumor } \\
\text { stain }\end{array}$ \\
\hline $\begin{array}{l}\text { Narasaki } \\
\text { et al. (89) }\end{array}$ & 2017 & 16 & $\begin{array}{l}2.5 \mathrm{mg} / \mathrm{L} \text { of } \\
\text { estimated liver } \\
\text { volume }\end{array}$ & Intravenous & intraop & Mini-FLARE & Open & $\begin{array}{l}6 \text { CholangioCA, } 5 \text { GB } \\
\text { cancer, } 2 \text { pancreatic } \\
\text { cancer, } 1 \text { ampullary } \\
\text { cancer, } 1 \text { CLM, } 1 \text { renal } \\
\text { cancer }\end{array}$ & $\begin{array}{l}\text { Segmental } \\
\text { stain }\end{array}$ \\
\hline $\begin{array}{l}\text { Kobayashi } \\
\text { et al. (90) }\end{array}$ & 2017 & 105 & $\begin{array}{c}0.25 \mathrm{mg} \text { ICG } \\
\text { diluted with } \\
\text { indigocarmine or } \\
2.5 \mathrm{mg} \text { ICG }\end{array}$ & $\begin{array}{c}\text { Intravenous or } \\
\text { injection into PV } \\
\text { branch }\end{array}$ & Intraop & Hammamatsu & Open & $\begin{array}{l}71 \text { HCC, } 25 \text { CLM, } \\
5 \text { CholangioCA, } \\
2 \text { other }\end{array}$ & $\begin{array}{l}\text { Segmental } \\
\text { stain }\end{array}$ \\
\hline $\begin{array}{l}\text { Nanashima } \\
\text { et al. (92) }\end{array}$ & 2018 & 3 & $0.5 \mathrm{mg} / \mathrm{kg}$ & Intravenous & $\begin{array}{l}\text { "Several days" } \\
\text { before surgery }\end{array}$ & ' Hammamatsu & Open & $3 \mathrm{HCC}$ & $\begin{array}{l}\text { Tumor } \\
\text { stain }\end{array}$ \\
\hline $\begin{array}{l}\text { Cheung } \\
\text { et al. (93) }\end{array}$ & 2018 & 20 & $0.5 \mathrm{mg} / \mathrm{kg}$ & Intravenous & $\begin{array}{c}10-14 \text { days } \\
\text { before surgery }\end{array}$ & Novadaq & Laparoscopic & $20 \mathrm{HCC}$ & $\begin{array}{l}\text { Tumor } \\
\text { stain }\end{array}$ \\
\hline $\begin{array}{l}\text { Peyrat } \\
\text { et al. (94) }\end{array}$ & 2018 & 43 & $\begin{array}{c}0.25 \mathrm{mg} / \mathrm{kg} \text {, } \\
\text { additional dilute } \\
\text { injections } \\
\text { intraoperatively }\end{array}$ & $\begin{array}{l}\text { Intravenous, PV } \\
\text { injection intraop }\end{array}$ & $\begin{array}{l}1 \text { day before } \\
\text { surgery, } \\
\text { Intraop }\end{array}$ & Fluoptics & Open & $\begin{array}{l}2 \mathrm{HCC}, \\
2 \text { CholangioCA, } \\
36 \text { CLM, } 3 \text { other }\end{array}$ & $\begin{array}{l}\text { Tumor } \\
\text { stain }\end{array}$ \\
\hline $\begin{array}{l}\text { Nomi et al. } \\
\text { (95) }\end{array}$ & 2018 & 16 & $1.5 \mathrm{mg}$ & Intravenous & Intraop & Novadaq & Laparoscopic & Not reported & $\begin{array}{l}\text { Segmental } \\
\text { stain }\end{array}$ \\
\hline $\begin{array}{l}\text { He et al. } \\
(98)\end{array}$ & 2019 & 2 & $0.5 \mathrm{mg} / \mathrm{kg}$ & Intravenous & $\begin{array}{l}\text { 72-96 hr } \\
\text { before surgery }\end{array}$ & Hammamatsu & Open & $2 \mathrm{HCC}$ & $\begin{array}{l}\text { Tumor } \\
\text { stain }\end{array}$ \\
\hline $\begin{array}{l}\text { Urade } \\
\text { et al. (99) }\end{array}$ & 2019 & 3 & $2.5 \mathrm{mg}$ & Intravenous & Intraop & Olympus & Laparoscopic & $\begin{array}{l}2 \mathrm{HCC}, 1 \text { liver } \\
\text { metastasis }\end{array}$ & $\begin{array}{l}\text { Segmental } \\
\text { stain }\end{array}$ \\
\hline $\begin{array}{l}\text { Souzaki } \\
\text { et al. (100) }\end{array}$ & 2019 & 5 & $0.5 \mathrm{mg} / \mathrm{kg}$ & Intravenous & $\begin{array}{l}18-138 \text { hours } \\
\text { before surgery }\end{array}$ & Not reported & Open, VATS & 5 hepatoblastoma & $\begin{array}{l}\text { Tumor } \\
\text { stain }\end{array}$ \\
\hline $\begin{array}{l}\text { Yoshioka } \\
\text { et al. (101) }\end{array}$ & 2019 & 1 & $0.5 \mathrm{mg} / \mathrm{kg}$ & Intravenous & $\begin{array}{l}2 \text { days before } \\
\text { surgery }\end{array}$ & Novadaq & Laparoscopic & $1 \mathrm{HCC}$ recurrent & $\begin{array}{l}\text { Tumor } \\
\text { stain }\end{array}$ \\
\hline $\begin{array}{l}\text { Marino } \\
\text { et al. (102) }\end{array}$ & 2019 & 20 & $2.5 \mathrm{mg}$ & $\begin{array}{c}\text { Injection into PV } \\
\text { branch }\end{array}$ & Intraop & Intuitive & Robotic & Not reported & $\begin{array}{l}\text { Segmental } \\
\text { stain }\end{array}$ \\
\hline
\end{tabular}

PV, portal vein; VATS, video assisted thoracoscopic surgery; HCC, hepatocellular carcinoma; CLM, colorectal liver metastasis; CholangioCA, cholangiocarcinoma. 

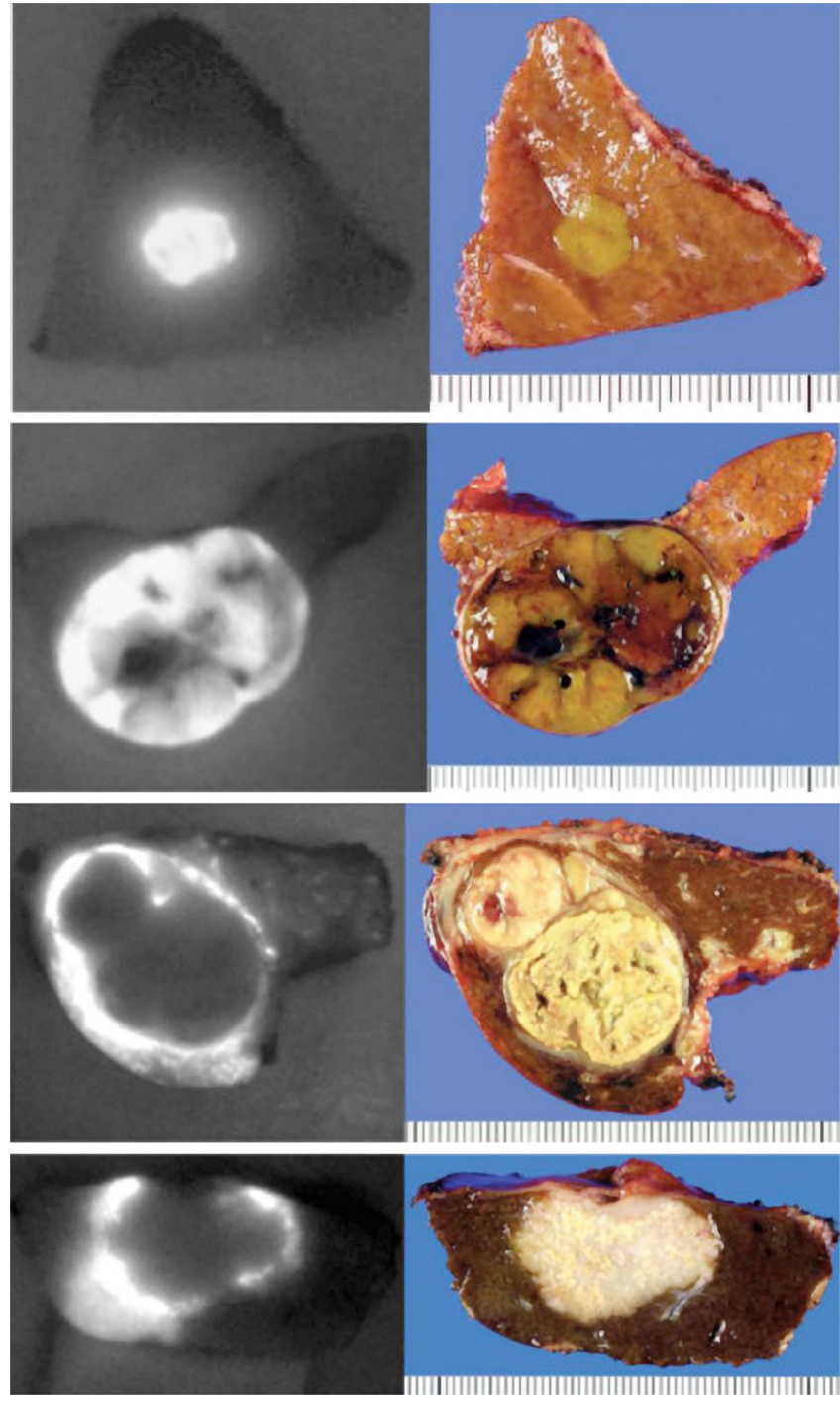

Figure 1 Differential patterns of fluorescence signals on the cut surface of different liver cancers using ICG. ICG administered pre-operatively gives a fluorescence signal over the liver when imaged with a NIR-fluorescence camera. The patterns can be classified into bright homogenous "total" fluorescence type (A) well-differentiated hepatocellular carcinoma (HCC), partial fluorescence type (B) moderately differentiated HCC, and rimtype fluorescence (C), poorly differentiated HCC (upper) and CLM (lower). Adapted from (104). ICG, indocyanine green; CLM, colorectal liver metastases.

to be performed to determine the long-term outcomes of fluorescence guided oncologic surgery.

\section{ICG and minimally invasive liver surgery}

Fluorescence navigation using a NIR wavelength is wellsuited for minimally-invasive liver surgery since this is already an environment where the surgeon is interacting with a monitor for visualization. Within four years of introduction of NIR fluorescence technology to open surgeries, NIRenabled fluorescence laparoscopes were commercially available. In 2012, Ishizawa et al. first reported the initial experience of laparoscopic fluorescence-imaging guidance to delineate hepatic segments during resection (107). Kudo et al. reported in 2014 on the first series of patients undergoing laparoscopic hepatectomy using a positive fluorescence signal to identify the liver surface tumors (79). Of the 33 papers identified using ICG for FGS of liver lesions, 10 discuss using a minimally-invasive approach, either laparoscopic or robotic. Authors of these studies especially note that the use of fluorescence in laparoscopy was especially useful for identifying small sub-centimeter sub-capsular lesions that were not readily evident under bright-light visualization (108). They note the added benefit of fluorescence for visualization in these minimallyinvasive approaches, especially that contrast enhancement compensates for the inability of the surgeon receive manual tactile feedback. Additionally image guidance was useful at superficial depths where IOUS may not readily detect these lesions. Fluorescence-navigation technology assisted in increasing the sensitivity of detecting lesions and localizing the resection margins in minimally-invasive settings.

Currently ongoing clinical trials using ICG in liver surgery are summarized in Table 5, however the work is still limited, focusing on feasibility, accuracy, and detections rates. There is limited information on outcomes, but with further experience, as well as expansion and maturation of this technology, more data should become available.

\section{ICG in liver transplants}

The ability to use ICG to delineate boundaries of liver segments, visualize the biliary tree and directly assess perfusion without directly cannulating the vasculature makes it uniquely applicable to the field of transplant surgery in both living donor liver transplants (LDLT) and for liver transplant recipients in general. The technology allows donor liver parenchyma to be precisely transected at the segmental interfaces, identify aberrant anatomy, check for bile leaks and evaluate the perfusion and function of the residual liver after donor partial hepatectomy. Mizuno et al. first used ICG to delineate aberrant anatomy in a 


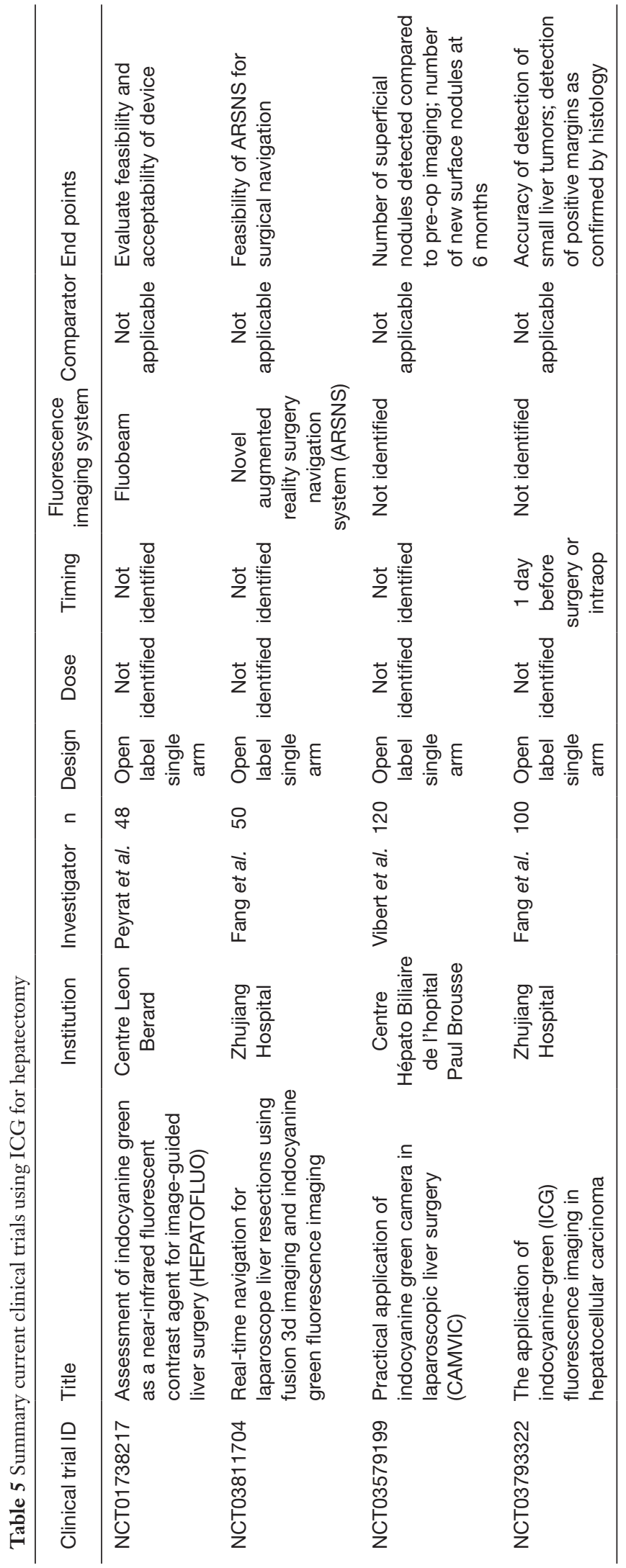

LDLT and further expand the application by using ICG fluorescent-cholangiogram to determine the point of transection of the bile duct $(109,110)$. For liver transplant recipients, the technology allows surgeons to directly evaluate vascular anastomoses without instrumentation or cannulation, check for bile leaks and additionally gives an indicator of synthetic function as the fluorophore undergoes biliary excretion. Kubota et al. first used this technology in 3 patients receiving LDLT to evaluate vascular anastomoses (111). Recipients were imaged 10 seconds after injection and showed adequate flow through both the hepatic artery and portal vein. Forty minutes after the initial injection, there was biliary excretion of the dye showing appropriate biliary function and all patients recovered uneventfully. Figueroa et al. reported on the largest study of liver recipients using this technology: 72 patients received intravenous injections of ICG and perfusion patterns over the liver surface were evaluated and categorized as homogenous, non-perfused areas, and patchy perfusion throughout (112). Patients with patchy perfusion had a higher rate of primary graft dysfunction of $60 \%$ compared to patients with non-perfused areas (30\%) and patients with homogenous perfusion (17\%).

\section{Tumor-specific fluorescence imaging for HPB surgery}

While imaging with fluorophores alone is useful for evaluating surface anatomy of the liver and visualizing hepatic lesions, the technology is sensitive, but not specific. Not all nodules that exhibit a fluorescence signal are malignant. While we are still accumulating more knowledge on the use of fluorescence pattern recognition, especially using ICG, there is not one signal intensity or pattern that clearly indicates malignancy. While the decision is clear for fluorescent lesions that clearly correlate with pre-operative imaging, it is unclear what to do for these indeterminate lesions where the location may change the extent of planned surgery. The technology often identifies additional lesions and after these lesions are resected, histologic examination shows that not all are malignant. Case-series reporting on additional lesions discovered by NIR fluorescence imaging describe false-positive fluorescent nodules, especially in the setting of cirrhosis. False positive rates are variable and can be as high as $40 \%$ and up to $87 \%$ in cirrhotic livers (78). Tanaka et al. report that the positive predictive value of ICG in cirrhotic livers can be as low as $5.4 \%$ compared to $100 \%$ in healthy livers (78). While those numbers are extreme, most groups use a combination of clinical judgment, bright- 

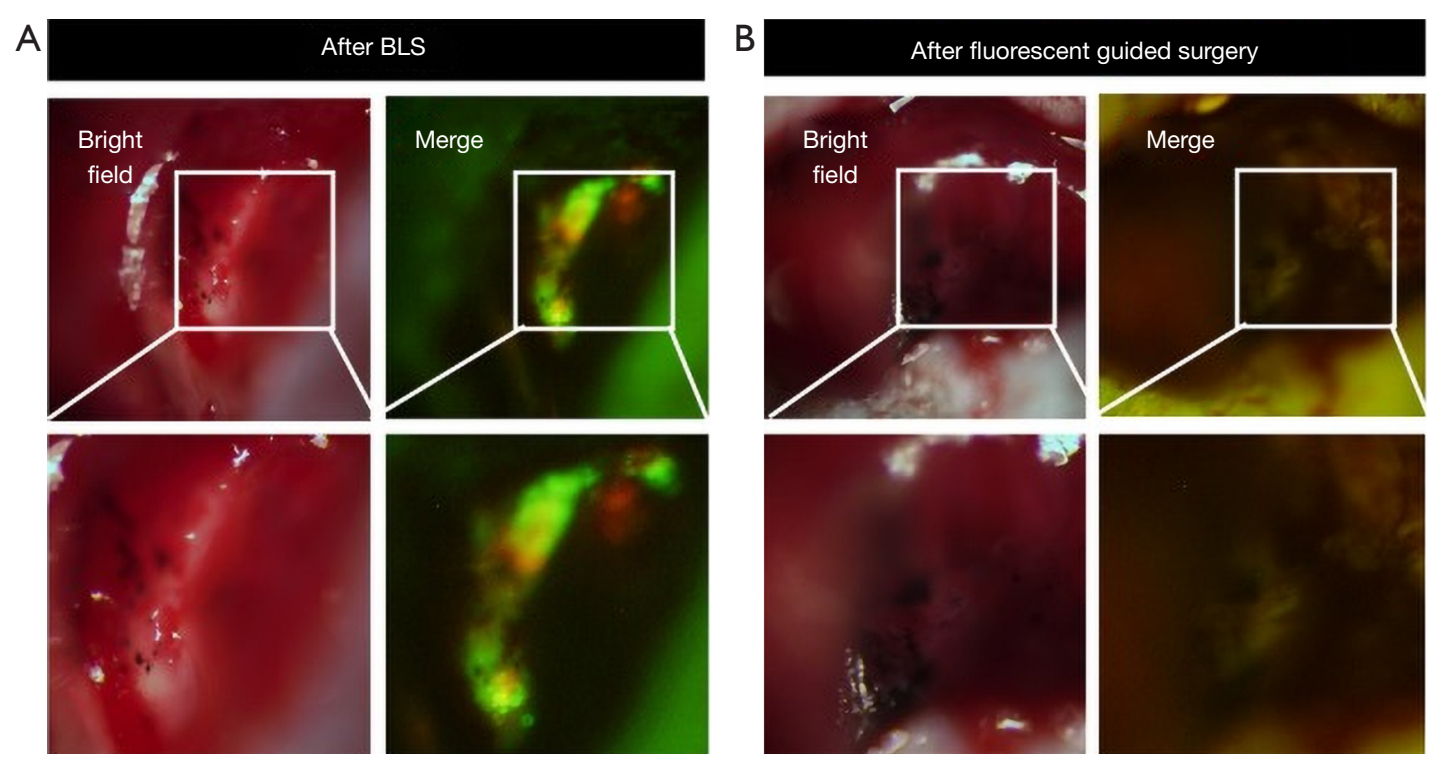

Figure 2 Visualizing a liver metastasis with viral-GFP in an orthotopic model of colon cancer. OBP-401, a conditionally-replicative adenovirus expressing GFP, was injected into orthotopically-implanted colorectal liver metastases 3 days before surgical resection. After BLS, both a GFP fluorescence signal from OBP-401 and an RFP signal from RFP-labeled cells were detected in the surgical bed (A). After OBP-401-FGS, there were no residual cancer cells (B). Adapted from (117). GFP, green fluorescence protein.

light inspection, and contrast enhanced IOUS to indicate malignancy prior to resection (88).

The use of tumor-binding probes conjugated to fluorophores can confer further specificity to FGS. These probes use a variety of mechanisms to confer specificity to lesions. The most common approach is targeting using antigen-antibody binding, but other approaches such as peptide binding, selective protease activation, $\mathrm{pH}$ differential, or aberrant tumor metabolism are all viable techniques to selectively deliver a fluorescence signal to the target lesions while decreasing background noise.

Our lab has developed orthotopic mouse models of hepatic cancers, especially CLM (113-115). By either orthotopically implanting the tumor specimen or additionally serially selecting for cell line variants that form hepatic metastases, we are able to create clinically-relevant mouse models for use in further establish of tumor-specific fluorescence platforms (116).

Yano et al. used a genetically-engineered adenovirus expressing green fluorescence protein (GFP) with an orthotopic CLM mouse model to show efficacy for FGS (117). The adenovirus called OBP-401, is a conditionally-replicative adenovirus with the replication cassette under the control of the human telomerase reverse transcriptase (hTERT) promoter and a GFP gene under the control of a cytomegalovirus (CMV) promoter (118). The virus was administered directly into the tumor and imaging was performed 3 days after injection. A strong GFP signal was visualized at the tumor for FGS. The localization of OBP-401 GFP correlated with the red fluorescence protein (RFP) cells. Two groups of mice $(\mathrm{n}=16)$ underwent FGS $v s$. standard bright light surgery (BLS) and were evaluated 120 days after surgery. After BLS, there was still residual tumor at the surgical bed as indicated by GFP and RFP signals using fluorescence imaging (Figure $2 A$ ), but after FGS using OBP-401, there was no residual cancer remaining (Figure 2B). 94\% (15/16) mice that underwent BLS had large tumor recurrences compared to mice that underwent FGS 19\% $(3 / 16)(\mathrm{P}<0.001)$.

Hiroshima et al. also compared FGS vs. BLS using a orthotopic CLM model, but delivered fluorescence to the tumor with an intravenous injection of anticarcinoembryonic antigen (CEA) antibody conjugated to a $650 \mathrm{~nm}$ fluorophore (119). The antibody-fluorophore conjugate was successful at delineating the tumor over the liver with a best signal to noise ratio at 72 hours. After BLS, there was still residual tumor at the surgical bed compared to FGS under anti-CEA-DyLight650 navigation where no residual cancer was detectable (Figure $3 A$ ). Additionally, the wavelength of the dye showed 
A
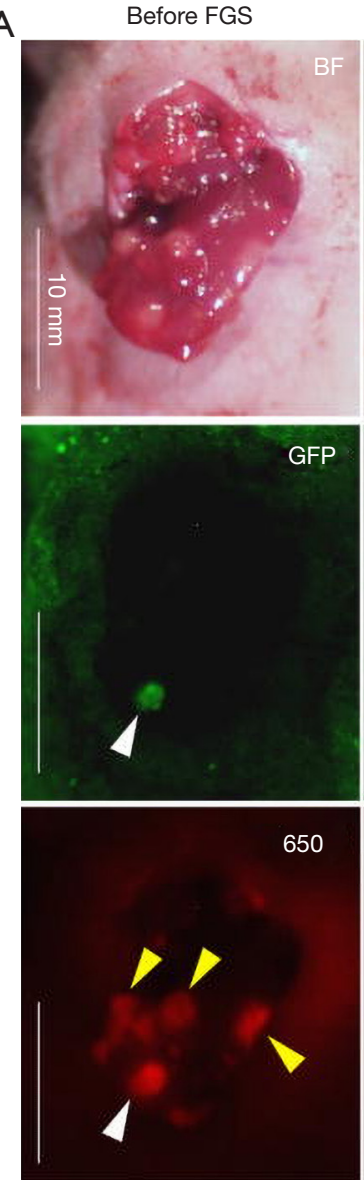

After FGS
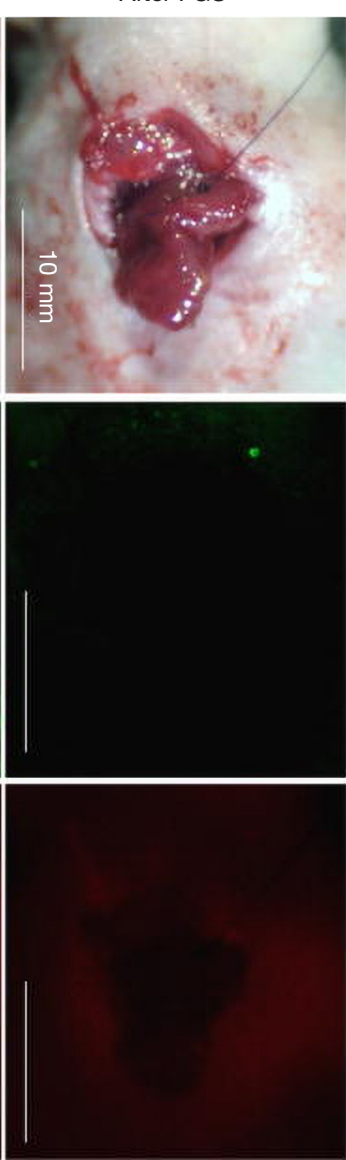

B
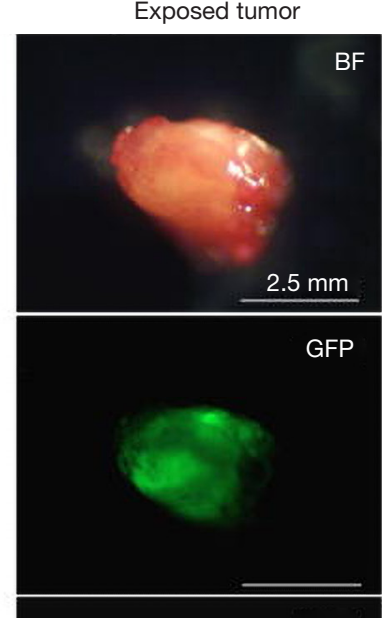

650
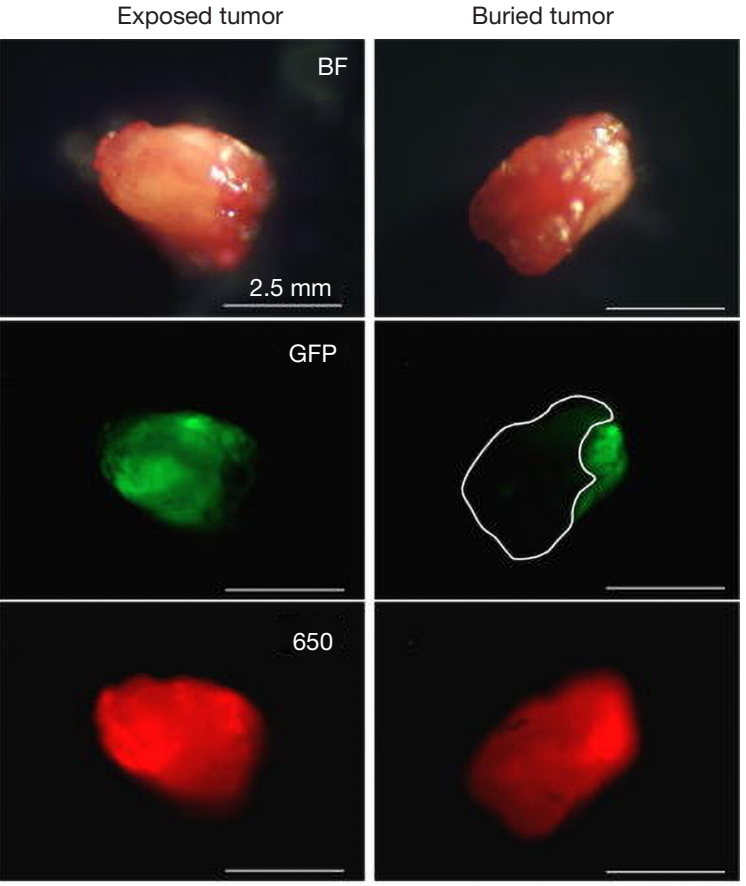

Figure 3 Visualizing a liver metastasis in an orthotopic model of colon cancer with a fluorescent antibody. Comparison between visible wavelength fluorescence and near-infrared fluorescence signal using anti-CEA antibody conjugated to DyLight650 visualized using a Mini Maglite ${ }^{\circledR}$ LED Pro flash light (Mag Instrument) with an excitation filter (ET640/30X, Chroma Technology Corporation) and a Canon EOS 60D digital camera with an EF-S18-55 IS lens (Canon) and an emission filter (HQ700/75M-HCAR, Chroma Technology Corporation). (A) The surface-exposed tumor (white arrow head) was clearly detected under both GFP and anti-CEA-DyLight650 navigation. In contrast, the tumors covered with normal tissues (yellow arrow heads) were detected only under anti-CEA-DyLight650 navigation. No residual tumor was detected after FGS. (B) Representative gross images of excised tumors (left panel: exposed tumor, right panel: buried tumor). Upper panels indicate bright field (BF) images; middle and lower panels indicate fluorescence images for GFP and DyLight 650 [650], respectively. The area surrounded by a white broken line indicates the buried part of the excised tumor. CEA650 fluorescence was able to penetrate normal liver tissue and visualize the buried part of the tumor, which was not detected by GFP fluorescence. Scale bars: 10 mm (A) and $2.5 \mathrm{~mm}$ (B). Adapted from (119). CEA, carcinoembryonic antigen; GFP, green fluorescence protein.

an improved fluorescence signal penetration in the presence of overlying tissue compared to GFP (Figure 3B). Diseasefree and overall survival were significantly higher in the FGS group compared to BLS. In these orthotopic mouse models of CLM, using tumor-specific fluorescence navigation for surgical resection, decreased the volume of residual disease and increased overall and disease-free survival.

Clinical translation of these approaches is rapid and underway (Table 6). Van Dam's group is evaluating the use of an anti-VEGF antibody conjugated to an $800 \mathrm{~nm}$ fluorophore, bevacizumab-800CW, in FGS of cholangiocarcinomas (NCT03620292). While the majority of these active clinical trials for tumor-specific probes are for colorectal and pancreatic cancers, the experience and concepts from these can be broadened into hepatic and biliary surgeries. Gutowski et al. report on 


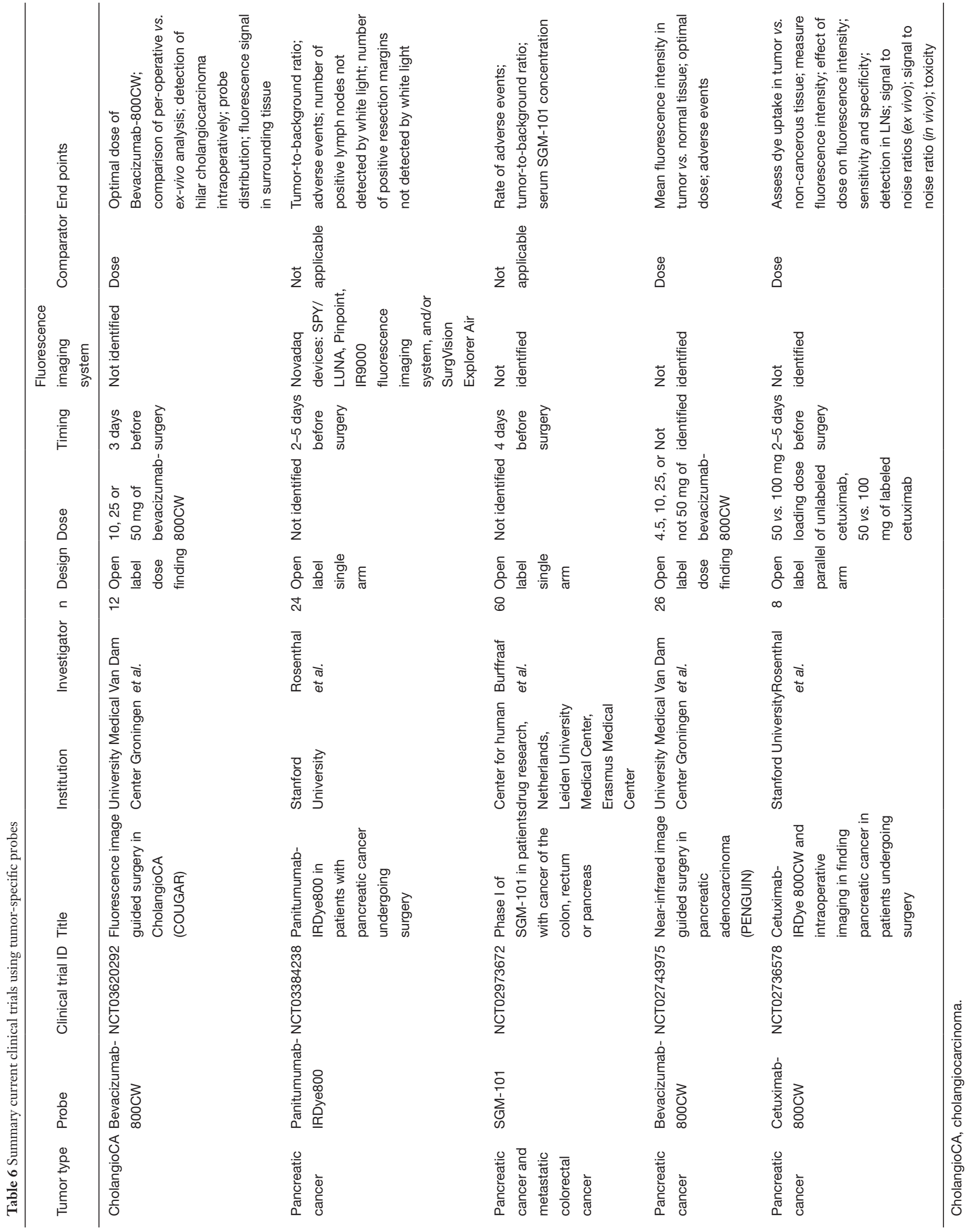



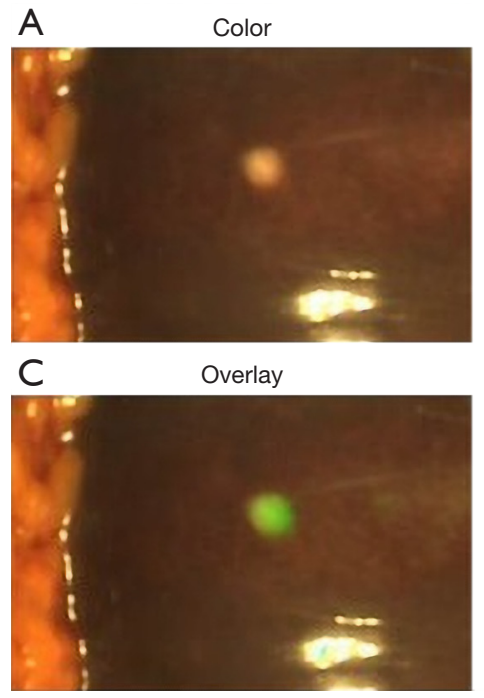

B

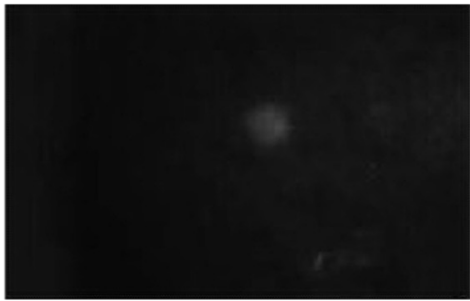

D Ex-vivo overlay

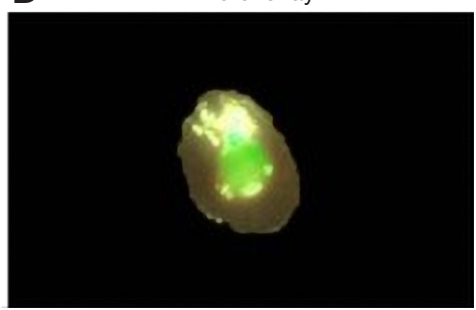

Figure 4 Fluorescence intraoperative imaging showing a liver metastasis of a pancreatic cancer using an anti-CEA antibody conjugated to SGM-101 near-infrared fluorophore using the Quest imaging system. Images shown in color (A), fluorescence (B), merged (C), and ex vivo imaging showing a slice from the same metastasis (D). Adapted from (122). CEA, carcinoembryonic antigen.

the results of clinical trial NCT02973672 using an antiCEA antibody conjugated to a $700 \mathrm{~nm}$ dye called SGM101 that successfully imaged colorectal and pancreatic cancers and this probe is advancing to a phase III clinical trial $(120,121)$. SGM-101 was found also to be able to label CLM as well as pancreatic cancer metastases to the liver as shown in Figure 4 (123). Rosenthal's group is working on an epidermal growth factor receptor (EGFR) conjugated to an $800 \mathrm{~nm}$ fluorophore for HPB and pancreatic cancers (NCT02736578, NCT03384238) (124-126).

These tumor-specific probes are still relatively early in their development, but the preliminary results are promising. With tumor-specific probes, there is enhanced and specific fluorescence at target lesions compared to a nonspecific dye such as ICG. Further work will need to be performed to optimize probe design, dose, schedule, and imaging devices. HPB procedures, especially those with minimally-invasive approaches, are cases where FGS can be used to potentially impact oncologic outcomes.

FGS is valuable for HPB surgery with both visible wavelength and NIR fluorophores. Nonspecific fluorophores are readily available and used in a variety of modalities to aid in visualization of desired structures. Nonspecific accumulation at tumors helps localize the lesions at the surface as well as deeper within the parenchyma. Tumor-specific probes are a promising advancement in FGS with a greater degree of specificity. While advancing rapidly, the technology is still relatively new and it will be very interesting to see its impact on outcomes in the next few years.

\section{Acknowledgments}

Funding: This work was supported by US National Cancer Institute grant numbers CA126023, CA142669 (MB and AntiCancer, Inc.), VA Merit Review grant number 1 I01 BX003856-01A1 (MB), NIH/NCI T32CA121938 (TM Lwin).

\section{Footnote}

Provenance and Peer Review: This article was commissioned by the Guest Editor (Dr. Yuman Fong) for the series "Imaging and HPB Surgery" published in Hepatobiliary Surgery and Nutrition. The article was sent for external peer review organized by the Guest Editor and the editorial office.

Reporting Checklist: The authors have completed the Narrative Review reporting checklist. Available at http:// dx.doi.org/10.21037/hbsn.2019.09.13

Conflicts of Interest: All authors have completed the ICMJE uniform disclosure form (available at http://dx.doi. 
org/10.21037/hbsn.2019.09.13). The series "Imaging and HPB Surgery" was commissioned by the editorial office without any funding or sponsorship. The authors have no other conflicts of interest to declare.

Ethical Statement: The authors are accountable for all aspects of the work in ensuring that questions related to the accuracy or integrity of any part of the work are appropriately investigated and resolved.

Open Access Statement: This is an Open Access article distributed in accordance with the Creative Commons Attribution-NonCommercial-NoDerivs 4.0 International License (CC BY-NC-ND 4.0), which permits the noncommercial replication and distribution of the article with the strict proviso that no changes or edits are made and the original work is properly cited (including links to both the formal publication through the relevant DOI and the license). See: https://creativecommons.org/licenses/by-nc-nd/4.0/.

\section{References}

1. Makuuchi M, Hasegawa H, Yamazaki S. Intraoperative ultrasonic examination for hepatectomy. Ultrasound Med Biol 1983;Suppl 2:493-7.

2. Clarke MP, Kane RA, Steele G, et al. Prospective comparison of preoperative imaging and intraoperative ultrasonography in the detection of liver tumors. Surgery 1989;106:849-55.

3. Hong G, Antaris AL, Dai H. Near-infrared fluorophores for biomedical imaging. Nat Biomed Eng 2017;1:s41551016-0010-6.

4. Adams KE, Ke S, Kwon S, et al. Comparison of visible and near-infrared wavelength-excitable fluorescent dyes for molecular imaging of cancer. J Biomed Opt 2007;12:024017.

5. Zhu B, Sevick-Muraca EM. A review of performance of near-infrared fluorescence imaging devices used in clinical studies. Br J Radiol 2015;88:20140547.

6. Peek MC, Charalampoudis P, Anninga B, et al. Blue dye for identification of sentinel nodes in breast cancer and malignant melanoma: a systematic review and metaanalysis. Future Oncol 2017;13:455-67.

7. DiSanto AR, Wagner JG. Pharmacokinetics of highly ionized drugs. I. Methylene blue--whole blood, urine, and tissue assays. J Pharm Sci 1972;61:598-602.

8. Sari YS, Tunali V, Tomaoglu K, et al. Can bile duct injuries be prevented? "A new technique in laparoscopic cholecystectomy”. BMC Surg 2005;5:14.

9. Makuuchi M, Hasegawa H, Yamazaki S. Ultrasonically guided subsegmentectomy. Surg Gynecol Obstet 1985;161:346-50.

10. Shou-wang C, Shi-zhong Y, Wen-ping L, et al. Sustained methylene blue staining to guide anatomic hepatectomy for hepatocellular carcinoma: Initial experience and technical details. Surgery 2015;158:121-7.

11. Lam CM, Lo CM, Liu CL, et al. Biliary complications during liver resection. World J Surg 2001;25:1273-6.

12. Guillaud A, Pery C, Campillo B, et al. Incidence and predictive factors of clinically relevant bile leakage in the modern era of liver resections. HPB 2013;15:224-9.

13. Liu CL, Fan ST, Lo CM, et al. Safety of donor right hepatectomy without abdominal drainage: a prospective evaluation in 100 consecutive liver donors. Liver Transpl 2005;11:314-9.

14. Matsui A, Tanaka E, Choi HS, et al. Real-time intraoperative near-infrared fluorescence identification of the extrahepatic bile ducts using clinically available contrast agents. Surgery 2010;148:87-95.

15. Ashitate Y, Stockdale A, Choi HS, et al. Real-time simultaneous near-infrared fluorescence imaging of bile duct and arterial anatomy. J Surg Res 2012;176:7-13.

16. Stummer W, Suero Molina E. Fluorescence Imaging/ Agents in Tumor Resection. Neurosurg Clin N Am 2017;28:569-83.

17. Hinnen P, de Rooij FW, van Velthuysen ML, et al. Biochemical basis of 5 -aminolaevulinic acid-induced protoporphyrin IX accumulation: a study in patients with (pre)malignant lesions of the oesophagus. Br J Cancer 1998;78:679-82.

18. Stummer W, Pichlmeier U, Meinel T, et al. Fluorescenceguided surgery with 5-aminolevulinic acid for resection of malignant glioma: a randomised controlled multicentre phase III trial. Lancet Oncol 2006;7:392-401.

19. Fritsch C, Lang K, Neuse W, et al. Photodynamic diagnosis and therapy in dermatology. Skin Pharmacol Appl Skin Physiol 1998;11:358-73.

20. Denzinger S, Burger M, Walter B, et al. Clinically relevant reduction in risk of recurrence of superficial bladder cancer using 5-aminolevulinic acid-induced fluorescence diagnosis: 8-year results of prospective randomized study. Urology 2007;69:675-9.

21. Schneider ARJ, Zöpf T, Arnold JC, et al. Feasibility and diagnostic impact of fluorescence-based diagnostic laparoscopy in hepatocellular carcinoma: a case report. Endoscopy 2002;34:831-4. 
22. Zöpf T, Schneider ARJ, Weickert U, et al. Improved preoperative tumor staging by 5 -aminolevulinic acid induced fluorescence laparoscopy. Gastrointest Endosc 2005;62:763-7.

23. Inoue Y, Tanaka R, Komeda K, et al. Fluorescence detection of malignant liver tumors using 5-aminolevulinic acid-mediated photodynamic diagnosis: principles, technique, and clinical experience. World J Surg 2014;38:1786-94.

24. Inoue $\mathrm{Y}$, Imai Y, Fujii K, et al. The utility of 5-aminolevulinic acid-mediated photodynamic diagnosis in the detection of intraoperative bile leakage. Am J Surg 2017;213:1077-82.

25. Honorato-Cia C, Martinez-Simón A, Cacho-Asenjo E, et al. Safety Profile of 5-Aminolevulinic Acid as a Surgical Adjunct in Clinical Practice: A Review of 207 Cases From 2008 to 2013. J Neurosurg Anesthesiol 2015;27:304-9.

26. Chung IWH, Eljamel S. Risk factors for developing oral 5 -aminolevulinic acid-induced side effects in patients undergoing fluorescence guided resection. Photodiagnosis Photodyn Ther 2013;10:362-7.

27. Kamisaka K, Listowsky I, Betheil JJ, et al. Competitive binding of bilirubin, sulfobromophthalein, indocyanine green and other organic anions to human and bovine serum albumin. Biochim Biophys Acta 1974;365:169-80.

28. Hashimoto M, Watanabe G. Hepatic Parenchymal Cell Volume and the Indocyanine Green Tolerance Test. J Surg Res 2000;92:222-7.

29. Landsman ML, Kwant G, Mook GA, et al. Lightabsorbing properties, stability, and spectral stabilization of indocyanine green. J Appl Physiol 1976;40:575-83.

30. DSouza AV, Lin H, Henderson ER, et al. Review of fluorescence guided surgery systems: identification of key performance capabilities beyond indocyanine green imaging. J Biomed Opt 2016;21:80901.

31. Robinson BL, Donohue JH, Gunes S, et al. Selective Operative Cholangiography: Appropriate Management for Laparoscopic Cholecystectomy. Arch Surg 1995;130:62530; discussion 630-1.

32. Flum DR. Intraoperative Cholangiography and Risk of Common Bile Duct Injury During Cholecystectomy. JAMA 2003;289:1639.

33. Ishizawa $\mathrm{T}$, Tamura $\mathrm{S}$, Masuda $\mathrm{K}$, et al. Intraoperative Fluorescent Cholangiography Using Indocyanine Green: A Biliary Road Map for Safe Surgery. J Am Coll Surg 2009;208:e1-4.

34. Ishizawa T, Bandai Y, Ijichi M, et al. Fluorescent cholangiography illuminating the biliary tree during laparoscopic cholecystectomy. Br J Surg 2010;97:1369-77.

35. Mitsuhashi N, Kimura F, Shimizu H, et al. Usefulness of intraoperative fluorescence imaging to evaluate local anatomy in hepatobiliary surgery. J Hepatobiliary Pancreat Surg 2008;15:508-14.

36. Aoki T, Murakami M, Yasuda D, et al. Intraoperative fluorescent imaging using indocyanine green for liver mapping and cholangiography. J Hepatobiliary Pancreat Sci 2010;17:590-4.

37. Tagaya N, Shimoda M, Kato M, et al. Intraoperative exploration of biliary anatomy using fluorescence imaging of indocyanine green in experimental and clinical cholecystectomies. J Hepatobiliary Pancreat Sci 2010;17:595-600.

38. Ishizawa T, Kaneko J, Inoue Y, et al. Application of fluorescent cholangiography to single-incision laparoscopic cholecystectomy. Surg Endosc 2011;25:2631-6.

39. Buchs NC, Hagen ME, Pugin F, et al. Intra-operative fluorescent cholangiography using indocyanin green during robotic single site cholecystectomy. Int J Med Robot 2012;8:436-40.

40. Kaneko J, Ishizawa T, Masuda K, et al. Indocyanine green reinjection technique for use in fluorescent angiography concomitant with cholangiography during laparoscopic cholecystectomy. Surg Laparosc Endosc Percutan Tech 2012;22:341-4.

41. Buchs NC, Pugin F, Azagury DE, et al. Real-time nearinfrared fluorescent cholangiography could shorten operative time during robotic single-site cholecystectomy. Surg Endosc 2013;27:3897-901.

42. Schols RM, Bouvy ND, Masclee AAM, et al. Fluorescence cholangiography during laparoscopic cholecystectomy: a feasibility study on early biliary tract delineation. Surg Endosc 2013;27:1530-6.

43. Schols RM, Bouvy ND, van Dam RM, et al. Combined vascular and biliary fluorescence imaging in laparoscopic cholecystectomy. Surg Endosc 2013;27:4511-7.

44. Spinoglio G, Priora F, Bianchi PP, et al. Real-time nearinfrared (NIR) fluorescent cholangiography in single-site robotic cholecystectomy (SSRC): a single-institutional prospective study. Surg Endosc 2013;27:2156-62.

45. Verbeek FPR, Schaafsma BE, Tummers QRJG, et al. Optimization of near-infrared fluorescence cholangiography for open and laparoscopic surgery. Surg Endosc 2014;28:1076-82.

46. Prevot F, Rebibo L, Cosse C, et al. Effectiveness of intraoperative cholangiography using indocyanine green (versus contrast fluid) for the correct assessment 
of extrahepatic bile ducts during day-case laparoscopic cholecystectomy. J. Gastrointest Surg 2014;18:1462-8.

47. Daskalaki D, Fernandes E, Wang X, et al. Indocyanine green (ICG) fluorescent cholangiography during robotic cholecystectomy: results of 184 consecutive cases in a single institution. Surg Innov 2014;21:615-21.

48. Larsen SS, Schulze S, Bisgaard T. Non-radiographic intraoperative fluorescent cholangiography is feasible. Dan Med J 2014;61:A4891.

49. Boni L, David G, Mangano A, et al. Clinical applications of indocyanine green (ICG) enhanced fluorescence in laparoscopic surgery. Surg Endosc 2015;29:2046-55.

50. Dip FD, Asbun D, Rosales-Velderrain A, et al. Cost analysis and effectiveness comparing the routine use of intraoperative fluorescent cholangiography with fluoroscopic cholangiogram in patients undergoing laparoscopic cholecystectomy. Surg Endosc 2014;28:1838-43.

51. Osayi SN, Wendling MR, Drosdeck JM, et al. Nearinfrared fluorescent cholangiography facilitates identification of biliary anatomy during laparoscopic cholecystectomy. Surg Endosc 2015;29:368-75.

52. Dip F, Roy M, Lo Menzo E, et al. Routine use of fluorescent incisionless cholangiography as a new imaging modality during laparoscopic cholecystectomy. Surg Endosc 2015;29:1621-6.

53. van Dam DA, Ankersmit M, van de Ven P, et al. Comparing Near-Infrared Imaging with Indocyanine Green to Conventional Imaging During Laparoscopic Cholecystectomy: A Prospective Crossover Study. J Laparoendosc Adv Surg Tech A 2015;25:486-92.

54. Kono Y, Ishizawa T, Tani K, et al. Techniques of Fluorescence Cholangiography During Laparoscopic Cholecystectomy for Better Delineation of the Bile Duct Anatomy. Medicine (Baltimore) 2015;94:e1005.

55. Dip F, Nguyen D, Montorfano L, et al. Accuracy of Near Infrared-Guided Surgery in Morbidly Obese Subjects Undergoing Laparoscopic Cholecystectomy. Obes Surg 2016;26:525-30.

56. Zroback C, Chow G, Meneghetti A, et al. Fluorescent cholangiography in laparoscopic cholecystectomy: the initial Canadian experience. Am J Surg 2016;211:933-7.

57. Zarrinpar A, Dutson EP, Mobley C, et al. Intraoperative Laparoscopic Near-Infrared Fluorescence Cholangiography to Facilitate Anatomical Identification: When to Give Indocyanine Green and How Much. Surg Innov 2016;23:360-5.

58. Igami T, Nojiri M, Shinohara K, et al. Clinical value and pitfalls of fluorescent cholangiography during singleincision laparoscopic cholecystectomy. Surg Today 2016;46:1443-50.

59. Boogerd LSF, Handgraaf HJM, Lam HD, et al. Laparoscopic detection and resection of occult liver tumors of multiple cancer types using real-time near-infrared fluorescence guidance. Surg Endosc 2017;31:952-61.

60. Graves C, Ely S, Idowu O, et al. Direct Gallbladder Indocyanine Green Injection Fluorescence Cholangiography During Laparoscopic Cholecystectomy. J Laparoendosc Adv Surg Tech A 2017;27:1069-73.

61. Maker AV, Kunda N. A Technique to Define Extrahepatic Biliary Anatomy Using Robotic Near-Infrared Fluorescent Cholangiography. J Gastrointest Surg 2017;21:1961-2.

62. Liu YY, Liao CH, Diana M, et al. Near-infrared cholecystocholangiography with direct intragallbladder indocyanine green injection: preliminary clinical results. Surg Endosc 2018;32:1506-14.

63. Hiwatashi K, Okumura H, Setoyama T, et al. Evaluation of laparoscopic cholecystectomy using indocyanine green cholangiography including cholecystitis: A retrospective study. Medicine (Baltimore) 2018;97:e11654.

64. Yoshiya S, Minagawa R, Kamo K, et al. Usability of Intraoperative Fluorescence Imaging with Indocyanine Green During Laparoscopic Cholecystectomy After Percutaneous Transhepatic Gallbladder Drainage. World J Surg 2019;43:127-33.

65. Ambe PC, Plambeck J, Fernandez-Jesberg V, et al. The role of indocyanine green fluoroscopy for intraoperative bile duct visualization during laparoscopic cholecystectomy: an observational cohort study in 70 patients. Patient Saf Surg 2019;13:2.

66. Kaibori M, Ishizaki M, Matsui K, et al. Intraoperative indocyanine green fluorescent imaging for prevention of bile leakage after hepatic resection. Surgery 2011;150:91-8.

67. Sakaguchi T, Suzuki A, Unno N, et al. Bile leak test by indocyanine green fluorescence images after hepatectomy. Am J Surg 2010;200:e19-23.

68. Bismuth H, Eshkenazy R, Arish A. Milestones in the evolution of hepatic surgery. Rambam Maimonides Med J 2011;2:e021.

69. Makuuchi M, Imamura H, Sugawara Y, et al. Progress in surgical treatment of hepatocellular carcinoma. Oncology 2002;62 Suppl 1:74-81.

70. Aoki T, Yasuda D, Shimizu Y, et al. Image-Guided Liver Mapping Using Fluorescence Navigation System with Indocyanine Green for Anatomical Hepatic Resection. 
World J Surg 2008;32:1763-7.

71. Inoue Y, Arita J, Sakamoto T, et al. Anatomical Liver Resections Guided by 3-Dimensional Parenchymal Staining Using Fusion Indocyanine Green Fluorescence Imaging. Ann Surg 2015;262:105-11.

72. Gotoh K, Yamada T, Ishikawa O, et al. A novel imageguided surgery of hepatocellular carcinoma by indocyanine green fluorescence imaging navigation. J Surg Oncol 2009;100:75-9.

73. Ishizawa T, Fukushima N, Shibahara J, et al. Real-time identification of liver cancers by using indocyanine green fluorescent imaging. Cancer 2009;115:2491-504.

74. Uchiyama K, Ueno M, Ozawa S, et al. Combined use of contrast-enhanced intraoperative ultrasonography and a fluorescence navigation system for identifying hepatic metastases. World J Surg 2010;34:2953-9.

75. Uchiyama K, Ueno M, Ozawa S, et al. Combined intraoperative use of contrast-enhanced ultrasonography imaging using a sonazoid and fluorescence navigation system with indocyanine green during anatomical hepatectomy. Langenbecks Arch Surg 2011;396:1101-7.

76. Ishizuka M, Kubota K, Kita J, et al. Intraoperative observation using a fluorescence imaging instrument during hepatic resection for liver metastasis from colorectal cancer. Hepatogastroenterology 2012;59:90-2.

77. Peloso A, Franchi E, Canepa MC, et al. Combined use of intraoperative ultrasound and indocyanine green fluorescence imaging to detect liver metastases from colorectal cancer. HPB 2013;15:928-34.

78. Tanaka T, Takatsuki M, Hidaka $M$, et al. Is a fluorescence navigation system with indocyanine green effective enough to detect liver malignancies? J Hepatobiliary Pancreat Sci 2014;21:199-204.

79. Kudo H, Ishizawa T, Tani K, et al. Visualization of subcapsular hepatic malignancy by indocyanine-green fluorescence imaging during laparoscopic hepatectomy. Surg Endosc 2014;28:2504-8.

80. Sakoda M, Ueno S, Iino S, et al. Anatomical laparoscopic hepatectomy for hepatocellular carcinoma using indocyanine green fluorescence imaging. J Laparoendosc Adv Surg Tech A 2014;24:878-82.

81. Tummers QRJG, Verbeek FPR, Prevoo HAJM, et al. First experience on laparoscopic near-infrared fluorescence imaging of hepatic uveal melanoma metastases using indocyanine green. Surg Innov 2015;22:20-5.

82. Yamamichi T, Oue T, Yonekura T, et al. Clinical application of indocyanine green (ICG) fluorescent imaging of hepatoblastoma. J Pediatr Surg 2015;50:833-6.
83. Barabino G, Porcheron J, Cottier M, et al. Improving Surgical Resection of Metastatic Liver Tumors With NearInfrared Optical-Guided Fluorescence Imaging. Surg Innov 2016;23:354-9.

84. Kaibori M, Matsui K, Ishizaki M, et al. Intraoperative Detection of Superficial Liver Tumors by Fluorescence Imaging Using Indocyanine Green and 5-aminolevulinic Acid. Anticancer Res 2016;36:1841-9.

85. Takahashi H, Zaidi N, Berber E. An initial report on the intraoperative use of indocyanine green fluorescence imaging in the surgical management of liver tumorss. J Surg Oncol 2016;114:625-9.

86. Zhang YM, Shi R, Hou JC, et al. Liver tumor boundaries identified intraoperatively using real-time indocyanine green fluorescence imaging. J Cancer Res Clin Oncol 2017;143:51-8.

87. Kawaguchi Y, Nomura Y, Nagai M, et al. Liver transection using indocyanine green fluorescence imaging and hepatic vein clamping. Br J Surg 2017;104:898-906.

88. Terasawa M, Ishizawa T, Mise Y, et al. Applications of fusion-fluorescence imaging using indocyanine green in laparoscopic hepatectomy. Surg Endosc 2017;31:5111-8.

89. Narasaki H, Noji T, Wada H, et al. Intraoperative RealTime Assessment of Liver Function with Near-Infrared Fluorescence Imaging. Eur Surg Res 2017;58:235-45.

90. Kobayashi Y, Kawaguchi Y, Kobayashi K, et al. Portal vein territory identification using indocyanine green fluorescence imaging: Technical details and short-term outcomes. J Surg Oncol 2017;116:921-31.

91. Lieto E, Galizia G, Cardella F, et al. Indocyanine Green Fluorescence Imaging-Guided Surgery in Primary and Metastatic Liver Tumors. Surg Innov 2018;25:62-8.

92. Nanashima A, Tominaga T, Sumida $Y$, et al. Indocyanine green identification for tumor infiltration or metastasis originating from hepatocellular carcinoma. Int J Surg Case Rep 2018;46:56-61.

93. Cheung TT, Ma KW, She WH, et al. Pure laparoscopic hepatectomy with augmented reality-assisted indocyanine green fluorescence versus open hepatectomy for hepatocellular carcinoma with liver cirrhosis: A propensity analysis at a single center. Asian J Endosc Surg 2018;11:104-11.

94. Peyrat $\mathrm{P}$, Blanc E, Guillermet $\mathrm{S}$, et al. HEPATOFLUO: A prospective monocentric study assessing the benefits of indocyanine green (ICG) fluorescence for hepatic surgery. J Surg Oncol 2018;117:922-7.

95. Nomi T, Hokuto D, Yoshikawa T, et al. A Novel Navigation for Laparoscopic Anatomic Liver Resection 
Using Indocyanine Green Fluorescence. Ann Surg Oncol 2018;25:3982.

96. Chiba N, Shimazu M, Ochiai S, et al. Resection of Hepatic Lesions Perfused by the Cholecystic Vein Using Indocyanine Green Navigation in Patients with cT2 Gallbladder Cancer. World J Surg 2019;43:608-14.

97. Alfano MS, Molfino S, Benedicenti S, et al. Intraoperative ICG-based imaging of liver neoplasms: a simple yet powerful tool. Preliminary results. Surg Endosc 2019;33:126-34.

98. He P, Huang T, Fang C, et al. Identification of extrahepatic metastasis of hepatocellular carcinoma using indocyanine green fluorescence imaging. Photodiagnosis Photodyn Ther 2019;25:417-20.

99. Urade T, Sawa H, Iwatani Y, et al. Laparoscopic anatomical liver resection using indocyanine green fluorescence imaging. Asian J Surg 2020;43:362-8.

100.Souzaki R, Kawakubo N, Matsuura T, et al. Navigation surgery using indocyanine green fluorescent imaging for hepatoblastoma patients. Pediatr Surg Int 2019;35:551-7.

101.Yoshioka M, Taniai N, Kawano Y, et al. Laparoscopic repeat hepatectomy with indocyanine green fluorescence navigation: A case report. J Nippon Med Sch 2019;86:291-5.

102. Marino MV, Builes Ramirez S, Gomez Ruiz M. The Application of Indocyanine Green (ICG) Staining Technique During Robotic-Assisted Right Hepatectomy: with Video. J Gastrointest Surg 2019;23:2312-3.

103. Maeda H, Wu J, Sawa T, et al. Tumor vascular permeability and the EPR effect in macromolecular therapeutics: a review. J Control Release 2000;65:271-84.

104. Ishizawa T, Harada N, Muraoka A, et al. Scientific Basis and Clinical Application of ICG Fluorescence Imaging: Hepatobiliary Canc er !2009-10-02 !2009-12-23 !2010-05-26 ! Open Surg Oncol J 2010;2:31-6.

105. Nakaseko Y, Ishizawa T, Saiura A. Fluorescence-guided surgery for liver tumors. J Surg Oncol 2018;118:324-31.

106. Handgraaf HJM, Boogerd LSF, Höppener DJ, et al. Longterm follow-up after near-infrared fluorescence-guided resection of colorectal liver metastases: A retrospective multicenter analysis. Eur J Surg Oncol 2017;43:1463-71.

107. Ishizawa T, Zuker NB, Kokudo N, et al. Positive and negative staining of hepatic segments by use of fluorescent imaging techniques during laparoscopic hepatectomy. Arch Surg Chic Ill 1960 2012;147:393-4.

108. Kawaguchi Y, Nagai M, Nomura Y, et al. Usefulness of indocyanine green-fluorescence imaging during laparoscopic hepatectomy to visualize subcapsular hard-toidentify hepatic malignancy. J Surg Oncol 2015;112:514-6.

109. Mizuno S, Isaji S. Indocyanine green (ICG) fluorescence imaging-guided cholangiography for donor hepatectomy in living donor liver transplantation. Am J Transplant 2010;10:2725-6.

110. Mizuno S, Inoue H, Tanemura A, et al. Biliary complications in 108 consecutive recipients with ductto-duct biliary reconstruction in living-donor liver transplantation. Transplant Proc 2014;46:850-5.

111. Kubota K, Kita J, Shimoda M, et al. Intraoperative assessment of reconstructed vessels in living-donor liver transplantation, using a novel fluorescence imaging technique. J Hepatobiliary Pancreat Surg 2006;13:100-4.

112. Figueroa R, Golse N, Alvarez FA, et al. Indocyanine green fluorescence imaging to evaluate graft perfusion during liver transplantation. HPB 2019;21:387-92.

113.Fu XY, Besterman JM, Monosov A, et al. Models of human metastatic colon cancer in nude mice orthotopically constructed by using histologically intact patient specimens. Proc Natl Acad Sci U S A 1991;88:9345-9.

114. Hoffman RM. Patient-derived orthotopic xenografts: better mimic of metastasis than subcutaneous xenografts. Nat Rev Cancer 2015;15:451-2.

115. Kubota T. Metastatic models of human cancer xenografted in the nude mouse: the importance of orthotopic transplantation. J Cell Biochem 1994;56:4-8.

116.Hoffman RM. Orthotopic metastatic mouse models for anticancer drug discovery and evaluation: a bridge to the clinic. Invest New Drugs 1999;17:343-59.

117. Yano S, Takehara K, Miwa S, et al. Improved Resection and Outcome of Colon-Cancer Liver Metastasis with Fluorescence-Guided Surgery Using In Situ GFP Labeling with a Telomerase-Dependent Adenovirus in an Orthotopic Mouse Model. PloS One 2016;11:e0148760.

118. Kishimoto H, Kojima T, Watanabe $\mathrm{Y}$, et al. In vivo imaging of lymph node metastasis with telomerase-specific replication-selective adenovirus. Nat Med 2006;12:1213-9.

119. Hiroshima Y, Lwin TM, Murakami T, et al. Effective fluorescence-guided surgery of liver metastasis using a fluorescent anti-CEA antibody. J Surg Oncol 2016;114:951-8.

120. Gutowski M, Framery B, Boonstra MC, et al. SGM-101: An innovative near-infrared dye-antibody conjugate that targets CEA for fluorescence-guided surgery. Surg Oncol 2017;26:153-62.

121. Framery B, Gutowski M, Dumas K, et al. Toxicity and pharmacokinetic profile of SGM-101, a fluorescent anti- 
CEA chimeric antibody for fluorescence imaging of tumors in patients. Toxicol Rep 2019;6:409-15.

122. Hoogstins CES, Boogerd LSF, Sibinga Mulder BG, et al. Image-Guided Surgery in Patients with Pancreatic Cancer: First Results of a Clinical Trial Using SGM-101, a Novel Carcinoembryonic Antigen-Targeting, Near-Infrared Fluorescent Agent. Ann Surg Oncol 2018;25:3350-7.

123. Hoogstins CES, Tummers QRJG, Gaarenstroom KN, et al. A Novel Tumor-Specific Agent for Intraoperative NearInfrared Fluorescence Imaging: A Translational Study in Healthy Volunteers and Patients with Ovarian Cancer. Clin Cancer Res 2016;22:2929-38.

124. Rosenthal EL, Warram JM, de Boer E, et al. Successful

Cite this article as: Lwin TM, Hoffman RM, Bouvet M. Fluorescence-guided hepatobiliary surgery with long and short wavelength fluorophores. HepatoBiliary Surg Nutr 2020;9(5):615639. doi: 10.21037/hbsn.2019.09.13
Translation of Fluorescence Navigation During Oncologic Surgery: A Consensus Report. J Nucl Med 2016;57:144-50.

125. Tummers WS, Miller SE, Teraphongphom NT, et al. Detection of visually occult metastatic lymph nodes using molecularly targeted fluorescent imaging during surgical resection of pancreatic cancer. HPB (Oxford) 2019;21:883-90.

126. Tummers WS, Miller SE, Teraphongphom NT, et al. Intraoperative Pancreatic Cancer Detection using TumorSpecific Multimodality Molecular Imaging. Ann Surg Oncol 2018;25:1880-8. 